\title{
Self-assembly and chemical processing of block copolymers: a roadmap towards a diverse array of block copolymer nanostructures ${ }^{\dagger}$
}

\author{
WYMAN Ian \& LIU GuoJun* \\ Department of Chemistry, Queen's University, 90 Bader Lane, Kingston, Ontario, K7L 3N6
}

Received May 2, 2013; accepted May 27, 2013

\begin{abstract}
Block copolymers can yield a diverse array of nanostructures. Their assembly structures are influenced by their inherent structures, and the wide variety of structures that can be prepared especially becomes apparent when one considers the number of routes available to prepare block copolymer assemblies. Some examples include self-assembly, directed assembly, coupling, as well as hierarchical assembly, which can yield assemblies having even higher structural order. These assembly routes can also be complemented by processing techniques such as selective crosslinking and etching, the former technique leading to permanent structures, the latter towards sculpted and the combination of the two towards permanent sculpted structures. The combination of these pathways provides extremely versatile routes towards an exciting variety of architectures. This review will attempt to highlight destinations reached by LIU Guojun and coworkers following these pathways.
\end{abstract}

block copolymers, self-assembly, chemical processing, crosslinking

\section{Introduction}

Block copolymers consist of two or more polymer chains (defined as blocks), which are covalently linked together. Because of this covalent linkage of two or more polymer chains, block copolymers provide versatile building blocks for a diverse variety of molecular structures [1,2]. Different polymer chains are often incompatible and tend to segregate from one another. Since copolymer blocks are linked together, this segregation is restricted somewhat and is thus described as microphase segregation [1, 3, 4], which occurs between different copolymer blocks under various conditions and among copolymers either dispersed in solution or in the solid state. This segregation behavior can be governed by the incompatibilities between different blocks (characterized by the Flory-Huggins interaction parameter, $\chi$ ) and

*Corresponding author (email: guojun.liu@chem.queensu.ca) $\dagger$ Contributed by LIU GuoJun (Queen’s University) is also influenced by the volume fractions $(f)$ of these copolymer blocks [3-6]. The final morphology typically gains curvature via transitions from lamellar to cylindrical and eventually spherical morphologies as the block distribution becomes less symmetric. The morphologies can become more complex among triblock and higher multiblock copolymers [2, 7-10]. Meanwhile, the rigidity of a given block can also influence the copolymer's final assembly structure [11]. Block copolymers can thus yield a diverse range of nanostructures through self-assembly $[6,12,13]$, or they can also be manipulated by external fields [14-22], templates [23-27], or other applied influences [28-30] toward a desired architecture via directed assembly [31-33]. In the solid phase, intricate block-segregation patterns are observed among solid-films [34], and even within solid microsphere particles [35, 36]. Significant attention has been directed toward block copolymer assembly in the solid state, particularly as films, and has been highlighted in reviews by Hamley [37], Tsarkova et al. [38], Zhang et al. [34], Albert and Epps [39], Fasolka and Mayes [40], and by Green and Limary [41]. 


\subsection{Micellar block copolymer assembly}

Selective solvents are those which dissolve only certain blocks of a block copolymer, but not the other blocks. If a block copolymer is dispersed in a selective solvent, the individual copolymer chains (or unimers) may aggregate together to form micelles. These aggregated micelles can be in equilibrium with the unimers when the copolymer exceeds its critical micelle concentration (CMC), while the unimers may predominate at lower concentrations [42]. In general, the poorly soluble blocks will collapse to minimize their exposure to the solvent, while the soluble blocks will stretch as they extend into solution. In a relatively simple case involving a diblock copolymer, the copolymer may form a core-corona (sometimes called core-shell) micelle, in which the collapsed insoluble block forms the micellar core at the center of the micelle, while the soluble block forms the corona that surrounds the core and extends into solution (Scheme 1).

Micellar assembly in solution is generally more complex than solid state assembly, as the relative solubilities of the component blocks with the prevailing solvent can determine the morphologies of block copolymer micelles and their derivatives, particularly within block-selective solvents. In addition, the degree of swelling of a particular copolymer block is also influenced by its solubility, which adds further diversity to the potential assembly structures. The diverse array of block copolymer morphologies available from assembly in solution was demonstrated by Zhang and Eisenberg et al. [43, 44], who observed six different morphologies among a series of polystyrene-block-poly(acrylic acid) (PS- $b$-PAA) copolymers with varying block ratios within a block-selective solvent. The differing solubilities of the individual copolymer blocks can also contribute to the complexity of their assembly structures, even when these solubility differences are only subtle. In addition to core-corona

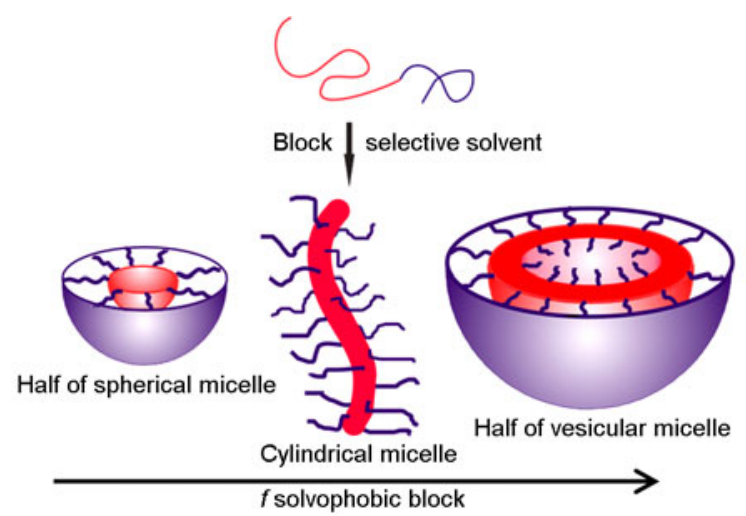

Scheme 1 Micelle formation by the aggregation of a diblock copolymer (top) in a selective solvent. In this example, the insoluble block (red) collapses to form the micellar core, and the soluble block (blue) forms the corona chains that extend into solution. The micellar structures shown here include a cross-sectional view of a spherical micelle (bottom left), a cylindrical micelle (bottom center), and a cross-sectional view of a vesicular micelle (bottom right). morphologies, block copolymer micelles can also exhibit highly intricate multicompartment morphologies, such as "sphere on sphere" raspberry structures, hamburger micelles, segmented cylinders, or various other elaborate structures [8, 45]. Multicompartment micelles generally require two core-forming (or alternatively corona-forming) blocks, and thus most examples are formed from mixtures of block copolymers, ABC triblock or multiblock copolymers, or miktoarm copolymers. Moughton and coworkers [8] have recently authored a detailed review of multicompartment micelles, while Walther and Müller [45] have recently written an extensive review of Janus assemblies, including those of Janus micelles.

\subsection{Focus of this review}

This review will focus on block copolymer assembly strategies employed by the Liu group shown in Scheme 2, such as self-assembly, crosslinking [46], structural etching [47, 48], and hierarchical assembly [49], and will also include examples of structural destinations that can be reached through these pathways. The majority of the examples highlighted in this review will have been prepared in solution as micelles or through micellar precursors. Although the main emphasis will involve examples prepared in by Guojun Liu and coworkers, relevant work from other researchers will be included as well. This combination of synthetic, self-assembly, and processing strategies leads to a diverse range of block copolymer nanostructures, including microspheres $[35,50$, $51]$, nanospheres [52, 53], bumpy spheres [54, 55], vesicles $[56,57]$, tadpoles [58-60], macrocycles [61], nanofibers [62, 63], nanotubes [64, 65], thin films containing nanochannels [66-69], miktoarm copolymers [70], helices [71-73], crosslinked polymer brushes [74], and Janus particles [75]. These structures also have a variety of potential applications, such as drug delivery [76], separations [77, 78], assay systems [51, 55], as catalysts [79], materials for superamphiphobic surfaces $[80,81]$, and improved friction reduction among lubricating oils $[82,83]$.

\section{The roads: self-assembly, directed assembly, crosslinking, and structural etching}

Most block copolymer nanostructures prepared in our lab are initially prepared through three general steps including polymer design, synthesis, and assembly (Scheme 2) [84]. The third step may involve either self-assembly [6, 12, 85-89] or directed assembly [23, 31, 90], with the block copolymers as the building blocks. At this stage the block copolymer building blocks assemble into ordered structures such as micelles in solution $[42,91,92]$ or as solid films [37], and this process is normally accompanied with microphase segregation. Alternatively, architectural polymer nanostructures are formed individually from their unimers 


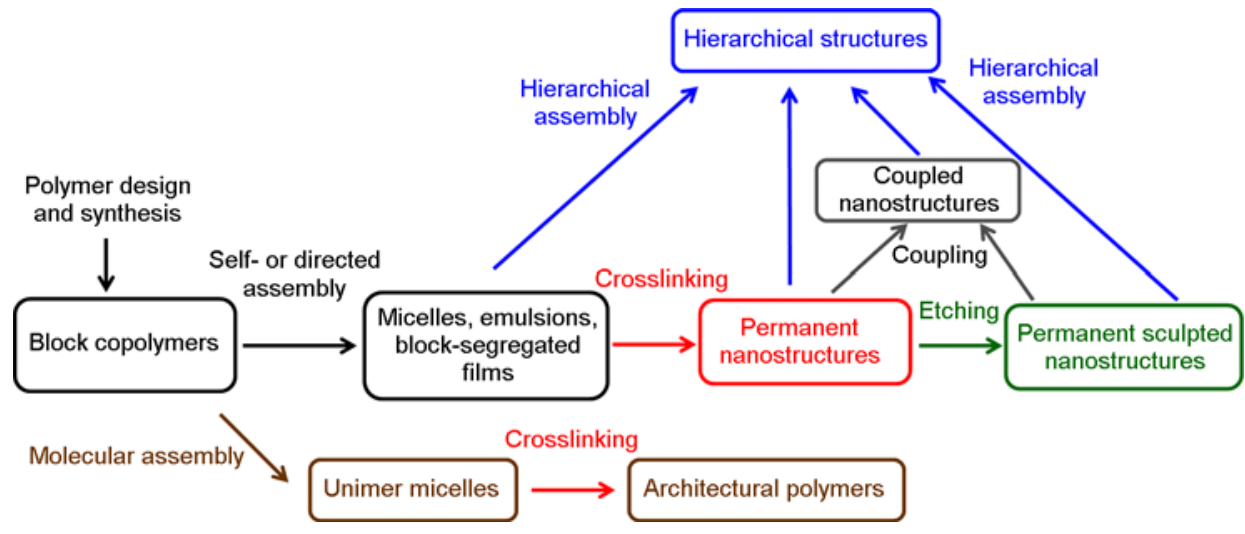

Scheme 2 Routes followed by Liu et al. towards various block copolymer nanostructures. A common route towards most of our structures involves polymer design, synthesis, and assembly to prepare micelles or block-segregated solids via either self-assembly or directed assembly. Often, crosslinking is performed to obtain permanent nanostructures. This can then be followed by degradation or etching to yield permanent sculpted nanostructures. Permanent nanostructures or permanent sculpted nanostructures may be coupled with other nanostructures (either similar or different) to produce coupled nanostructures. In some cases nanostructures may behave as building blocks for a second assembly process, or a hierarchical assembly, thus leading to hierarchical structures. Alternatively, a block copolymer may undergo molecular assembly to form architectural polymers that are based on individual unimers rather than assemblies of multiple polymer chains.

via intrachain assembly, rather than the aggregation of multiple unimer units [93-95]. These intrachain, or molecular, assemblies are often subjected to chemical processing such as crosslinking or sculpting to yield the final architectural polymer structure. These processing techniques are also employed for self-assembly and directed assembly aggregates of multiple polymer chains.

In our lab, crosslinking is normally employed as a fourth step to permanently lock the assembly structures. Such crosslinking is applied selectively to a block or domain that is responsive to the crosslinking technique (such as selectively locking PCEMA domains via photocrosslinking). Some examples of permanent nanostructures prepared this way include nanospheres [46], microspheres [35], and nanofibers [62, 96]. Crosslinking is sometimes followed by a degradation step, which involves selectively etching domains to yield void spaces or channels in the nanostructure to yield permanent sculpted structures. Members of this family include porous or hollow spheres [76, 97], nanotubes [64], and thin films containing nanochannels [66]. Sculpted nanostructures or permanent sculpted nanostructures can provide ideal hosts for guests such as organic molecules [76] or transition metals [52]. Alternatively, this process also yields porous nanostructures [50,65, 98] and membranes [66-69], which may be used for separations or for absorbing contaminants from their surroundings [77, 78, 99].

Permanent nanostructures or permanent sculpted nanostructures may be coupled together, or they may undergo hierarchical assembly to yield more complex nanostructures. Hierarchical assembly in this case involves the assembly of nanostructures to form even more complex ordered nanostructures, or "superstructures". This process is thus a higher order analog of block copolymer self-assembly, with block copolymer nanostructures serving as building blocks. A hierarchical analog of directed assembly can also be performed, as controlled (or programmed) hierarchical assembly $[49,100]$. In our lab, the coupling process typically involves the linkage together of two or more individual nanostructures [101, 102]. Thus the individual nanostructures serve as intermediate units of a more complex, hybrid nanostructure. In comparison, coupling is typically a chemical processing step performed actively by the designer, while hierarchical assembly often requires less input as it is an upper-tier analog of self- or directed assembly. The coupling process is sometimes followed by hierarchical assembly, with coupled structures aggregating together to form hierarchical systems [101, 102].

\subsection{Micellar structures from block copolymer self- assembly}

Great interest in block copolymer micelles has arisen since Eisenberg and coworkers $[43,44]$ demonstrated the diverse range of micellar morphologies available through assembly in block-selective solvents. Micelles are among the most common block copolymer assembly structures observed in solution, and are highlighted in reviews by Eisenberg et al. [103, 104], Tuzar and Kratochvil [105], Mortensen[106], Riess [42], Zhulina and Borisov [107], and by Leroux and coworkers [108]. The formation of polymer-based assemblies into various shapes bearing hair-like corona chains was recently reviewed by Chen [109]. Examples of micellar block copolymer assemblies have been prepared by the Liu group as well. Recently, Liu prepared a diverse range of micelles and micelle-like aggregates (MAs) from a single triblock copolymer, poly(tert-butyl acrylate) ${ }_{107}$-block-poly(2cinnamoyloxyethyl methacrylate) ${ }_{193}$-block-poly(glyceryl monomethacrylate $)_{115}\left(\mathrm{PtBA}_{107}-b\right.$-PCEMA ${ }_{193}-b$ - $\mathrm{PGMA}_{115}$, where the subscripts indicate the repeat unit numbers) [110]. In particular, micelles of $\mathrm{PtBA}_{107}-b$-PCEMA ${ }_{193}-b$ - $\mathrm{PGMA}_{115}$ 
were prepared in solvent mixtures of pyridine and methanol. While all three blocks are soluble in pyridine, methanol is selective for the terminal PtBA and PGMA blocks. Typically, the copolymer was dispersed into a gently heated solution mixture and stirred for two days. The structures of the resultant micelles varied according to the methanol volume fraction in the solution mixture $\left(f_{\mathrm{MeOH}}\right)$, yielding spherical and cylindrical micelles when $f_{\mathrm{MeOH}}$ was $80 \%$ and $90 \%$ respectively (Figure 1(b) and (c), respectively). In each of these structures, the PCEMA domain formed the micellar core and the PtBA and PGMA blocks formed the corona. At higher $f_{\mathrm{MeOH}}$ values of $95 \%$ and $100 \%$, vesicular (Figure 1(d)) and tubular (Figure 1(e)) structures formed, respec-

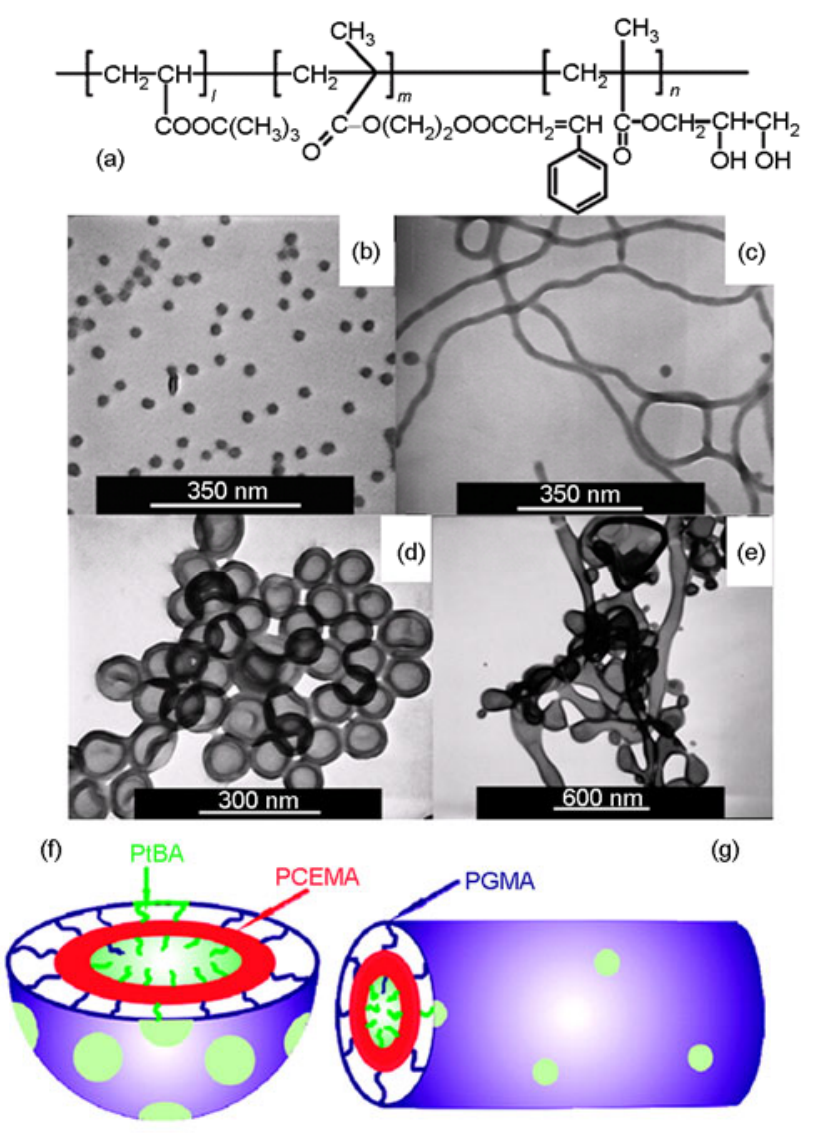

Figure 1 Structure of $\mathrm{PtBA}_{l}-b$-PCEMA ${ }_{m}-b$-PGMA ${ }_{n}$ (a). TEM images of spherical micelles (b) and cylindrical micelles (c), vesicles (d) and tubular micelle-like aggregates (MAs) (e) prepared in pyridine/methanol dispersions with $f_{\mathrm{MeOH}}=80 \%, 90 \%, 95 \%$, and $100 \%$, respectively. In these images the PCEMA domains were selectively stained using either $\mathrm{RuO}_{4}$ (image b) or $\mathrm{OsO}_{4}$ (images c-e) vapor [110]. Proposed structures of $\mathrm{PtBA}_{107}-b$ PCEMA $_{193}-b$-PGMA 115 vesicle-shaped (f) and tube shaped (g) MAs prepared in pyridine/methanol solvent mixtures with $f_{\mathrm{MeOH}}=95 \%$ and $100 \%$, respectively. The collapsed PCEMA domains formed the structural wall, while the majority of the external and internal corona chains were PGMA and PtBA, respectively. The coronas were not completely uniform, with small percentages of PtBA and PGMA chains localized on the external and internal walls. Since PtBA and PGMA are highly incompatible, the PtBA and PGMA domains were segregated from one another, with the minor PtBA components forming circular patches on the external surface [110]. Reprinted with permission from Ref. [110]. Copyright 2008 American Chemical Society. tively. The walls of both the vesicles and the hollow tubes were composed of PCEMA. Meanwhile, the majority of the corona chains on the exterior and interior surfaces of these structures were PGMA and PtBA chains, respectively (Figure $1(\mathrm{f})$ and $(\mathrm{g})$ ). However, these external and internal surfaces were not completely uniform, with minor components of PtBA present on the exterior and PGMA on the interior. Since the PtBA and PGMA corona chains were highly incompatible with one another, they underwent block-segregation, with the PtBA domains forming circular patches on the external PGMA surface.

Although micelles are often composed of identical unimers, they can also be prepared from mixtures of different block copolymer building blocks [111-119] or copolymer/homopolymer mixtures [120-123]. Such mixed aggregates have been highlighted in recent reviews by Yang et al. [124], and by Gohy and coworkers [125]. Some examples of mixed aggregates have been prepared by Liu and coworkers [126, 127]. In these examples, the unimers were $\mathrm{AB}$ and $\mathrm{AC}$ diblock copolymers, having one identical and one differing block. The common block would typically form the micellar core, while the differing blocks yielded a block-segregated corona. This may be considered as an alternate route towards nanostructures bearing intricate segregation patterns instead of using triblock copolymers, with a mixture of diblock copolymers forming the building blocks instead of a single triblock copolymer. Elaborate assemblies can also be prepared from block copolymer mixtures via emulsification strategies $[54,55]$, and an example is provided later in Section 2.2.1.

\subsubsection{Segmented cylinders and hamburgers}

Hamburger micelles are examples of multicompartment micelles consisting of distinct domains such as a central "meat filling" domain sandwiched between two "bun" domains, thus resembling a hamburger (Figure 2). Li and coworkers [128] prepared hamburger micelles and segmented cylinders from $\mu$-ABC miktoarm copolymers consisting of hydrophilic, a hydrophobic, and fluorinated chains.

Hamburger micelles and segmented cylinders can be prepared from linear block copolymers as well. For example, a series of hamburger-like micelles and segmented cylinders based on the triblock copolymer $\mathrm{PtBA}_{110}-b-\mathrm{PCEMA}_{195}-b$ PSGMA $_{115}$, where PSGMA corresponds to poly(succinated glyceryl monomethacrylate), was recently reported by Dupont and Liu [75]. The triblock copolymer was suspended into solvent mixtures of tetrahydrofuran (THF) and either 1- or 2-propanol. The three blocks were soluble in THF, while the terminal PtBA and PSGMA blocks were soluble in all THF/alcohol mixtures. Meanwhile PCEMA was insoluble in solvent mixtures with 1- or 2-propanol volume fractions $\left(f_{\text {propanol }}\right) \geqslant 95 \%$. Although all blocks were soluble in THF, the PSGMA block collapsed upon complexation with (-)-sparteine. To prepare the aggregates, $\mathrm{PtBA}_{110}-b$ - 


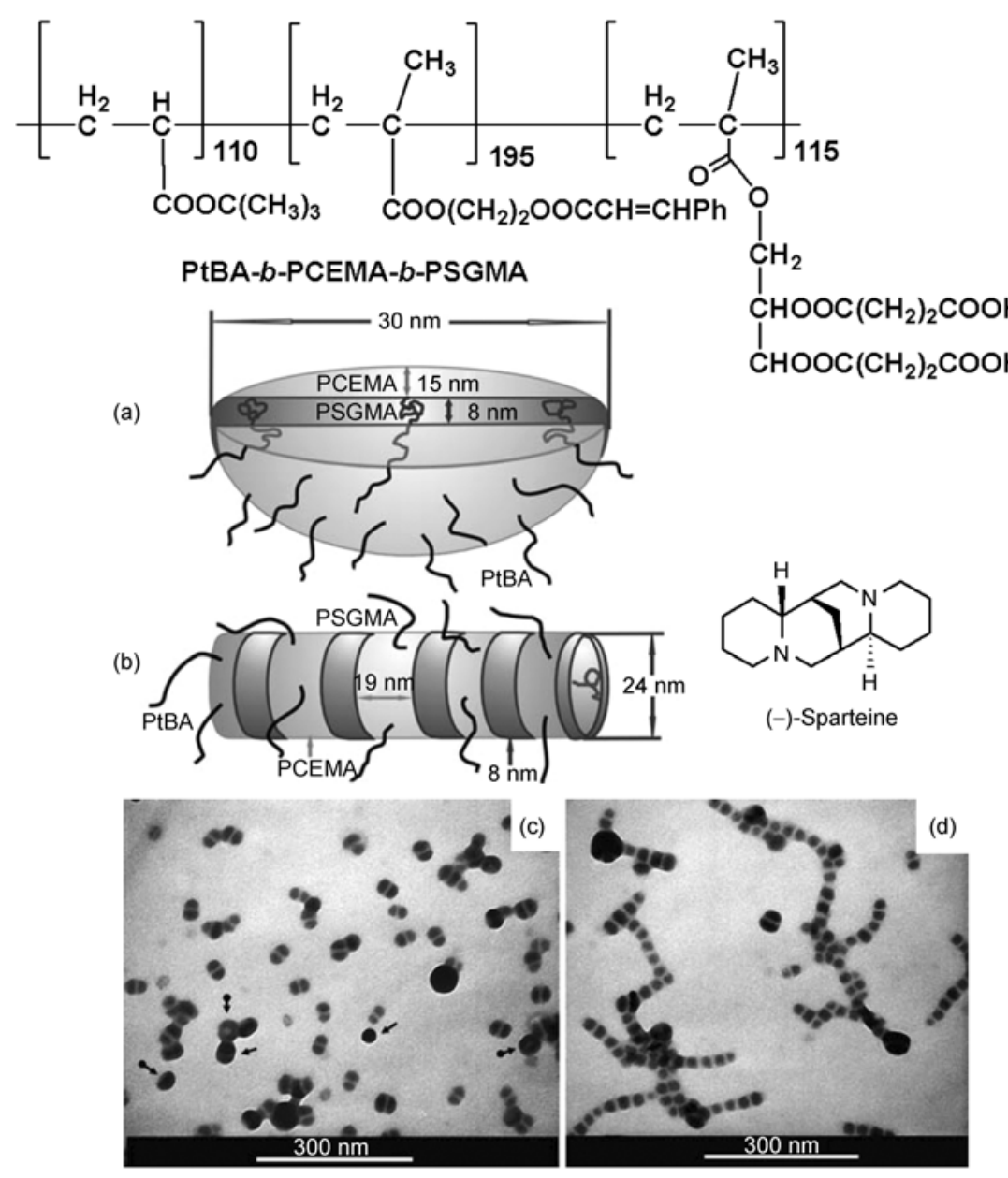

Figure 2 Schematic diagram of half of a hamburger-like micelle (a) and a segmented cylinder (b). The PSGMA block formed the hamburger filling, while the PCEMA domains formed the hamburger buns. The PtBA domains extended from the hamburger buns into the THF solvent. The segmented cylinders were similar to hamburger-like micelles, except that they consisted of multiple hamburgers that became fused together through the PCEMA buns [75]. TEM images showing samples composed primarily of hamburgers (c) and segmented cylinders (d). These samples were sprayed from mixtures of $\mathrm{THF} /(-)$-sparteine/1-propanol (c) or THF/(-)-sparteine/2-propanol (d). In both cases $f_{\text {propanol }}$ was $95 \%$, and the samples were stained with OsO $\mathrm{O}_{4}$. In image (c), the arrows with circular ends show vesicular aggregates, while the regular arrows show hamburgers sitting upright [75]. Reprinted with permission from Ref. [75]. Reprinted by permission of the Royal Society of Chemistry (RSC).

PCEMA $_{195}-b$-PSGMA 115 was dissolved in a small amount of THF, and (-)-sparteine was subsequently added in a small amount of propanol, causing collapse of PSGMA. More propanol was added until $f_{\text {propanol }}$ reached $95 \%$, inducing the PCEMA block to collapse. The choice of selective solvent influenced the dominant morphology. Hamburgers were dominant when 1-propanol was used, while segmented cylinders dominated when 2-propanol was chosen.

In addition, (-)-sparteine complexation with the PSGMA block played a key role, as it diminished the solubility of the PSGMA block and induced its collapse. Therefore, before the collapse of the PCEMA domains by the addition of the remaining propanol, the complexed PSGMA domain formed a micellar core, with the (-)-sparteine essentially serving as a template helping to direct the micellar assembly. The use of complexing agents to induce micellization or alter micelle behavior has been used by Kataoka and Harada [117], Kabanov et al. [129-131], Pochan et al. [132-135],
Shi et al. [136], and by numerous other researchers [137-141]. The solubility of the PSGMA block was also important. As mentioned above, the PSGMA block was soluble in THF, but only collapsed from solution upon complexation with (-)-sparteine. Because of this inherent solubility, the PSGMA domains were solvated with THF and the interfacial tension between PSGMA and the surrounding solvent was low. This allowed the PSGMA domains to remain somewhat exposed to the solvent, thus yielding hamburger-like micelles rather than spherical micelles with PSGMA isolated to the core. Dupont and Liu [75] proposed that the segmented cylinders formed due to fusion of hamburgers through their PCEMA buns as they approached one another.

\subsubsection{Twisted cylinders and helical block copolymer as- semblies}

While common block copolymer architectures include cyl- 
inders, spheres, and vesicles, examples of block copolymer-based helices have also been reported by various researchers [135, 142-147]. Such systems have also been highlighted in recent reviews by Ho and coworkers [148, 149], while Yashima et al. [150] have recently reviewed helical polymers in general. Helical block copolymer morphologies have been observed in the solid state [142], among spatially confined cylinder-forming block copolymers $[145,151]$, as well as in selective solvents [143]. Recently, Liu et al. reported helical assemblies of ABC triblock terpolymers in solvents that were selective for the terminal A and $\mathrm{C}$ blocks [71], or among other triblocks for which the solvent quality was marginal for the A block, poor for the central B block, and good for the $\mathrm{C}$ block $[72,73]$. Twisted cylinders were observed in the former example, while double and triple helices formed in the latter case. For example, $\mathrm{PBMA}_{n}-b-\mathrm{PCEMA}_{m}-b-\mathrm{PtBA}_{l}$ (where $n=350, m=160$, and $n=160$ or alternatively where $n=240, m=120$, and $n=$ 120 , respectively, and PBMA corresponds to poly(butyl methacrylate)) formed helices in solvents of marginal, poor, and good respective qualities for the PBMA, PCEMA, and PtBA blocks [72, 73]. The copolymer was initially dispersed into a good solvent, and then a selective solvent was added. After selective solvent addition, the sample solution was tightly sealed over an extended period to prevent solvent evaporation. During this period, the micelles gradually formed helical structures. Interestingly, these systems formed double helices as the major product, along with triple helices as minor products. Although multiple helices (i.e., double or triple helices) have been prepared previously from block copolymers in the solid state $[152,153]$ and in solution [135], this appears to be the first report of block copolymers forming multiple helices as the dominant species from solution self-assembly [72]. Multiple helical structures were also observed under these special solvent conditions for the above copolymers if their PtBA block had been either partially or fully hydrolyzed into PAA.

During the helix development (typically occurring over 24-6 weeks) [72, 73], the PBMA $_{n}-b-\mathrm{PCEMA}_{m}-b-\mathrm{PtBA}_{l}$ copolymer initially formed spherical micelles, which gradually became fused, yielding short cylindrical micelles (Figure 3). These cylinders grew into longer curved cylinders, which became intertwined with one another to yield double and triple helices. The cores of the initial spherical micelles consisted of PCEMA, while PBMA and PtBA formed their corona. The marginally soluble block played a key role in the multiple helix assembly under these special solvent conditions. The cylinders became intertwined so that the marginally soluble PBMA domains from different cylinders could associate with one another, thus reducing exposure to the surrounding solvent. Liu and coworkers proposed a packing scheme for these double (and triple) helices, as shown in Figure 3f. Due to the slow kinetics of this assembly process, the observed was highly dependent on the time-span provided for the structure to evolve. The influ-

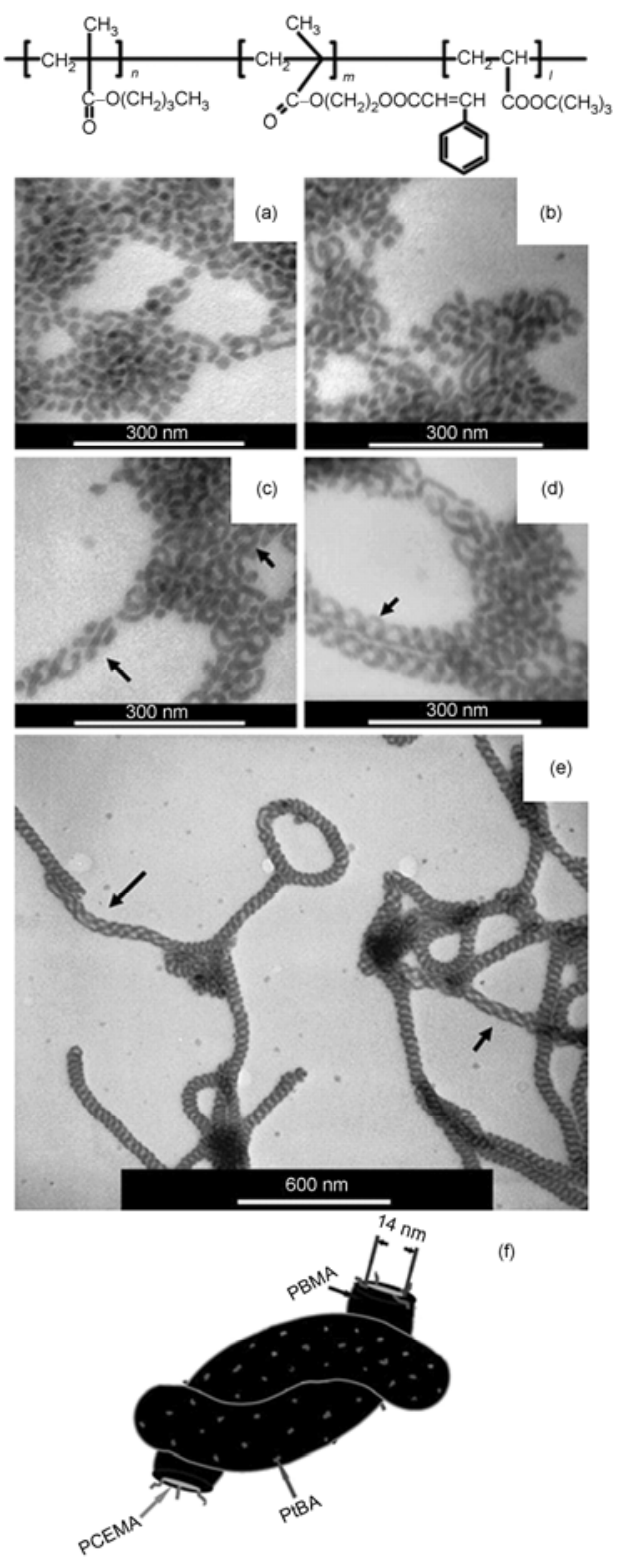

Figure 3 TEM images of $\mathrm{PBMA}_{350}-b$-PCEMA $\mathrm{P}_{160}-b$ - $\mathrm{PtBA}_{160}$ samples taken at various stages of their development into double and triple helices in dichloromethane/methanol solvent mixtures, with $f_{\mathrm{MeOH}}=82 \%$. Image (a) shows a mixture of spherical and cylindrical aggregates that were collected after 1 day of aging. In image (b) it is apparent that the cylinders became longer and began to curve. Image (c) shows a sample which had been aged 16 days, when the curved cylinders began to cross over one another (long arrow), and to form helices (shown by the short arrow). Image (d) shows a sample which was aged 24 days, when extended double helices were visible, with an example highlighted by the arrow. A sample aged for 3 months is shown in image (e) showing double helices as the major product, while triple helices (highlighted by the arrows) were also present. The samples shown above were stained with $\mathrm{OsO}_{4}$, which is selective for the PCEMA domains[72]. A schematic diagram of the chain packing of a double helix composed of intertwined PBMA- $b$-PCEMA- $b$ - PtBA cylinders is also shown (f). The PCEMA domains (light grey) form the cores of the cylinders, while PBMA (black) and PtBA (dark grey) form their coronas. The PtBA and PBMA domains are segregated somewhat, with the soluble PtBA chains favoring the exposed sides of the cylinders, and the PBMA domains favoring the sides facing the other cylinder, in order to reduce their contact with the solvent. Reprinted with permission from Ref. [72]. Copyright (2009) John Wiley and Sons. 
ence of kinetic trapping on achieving exotic assembly structures through different pathways has recently been reviewed by Hayward and Pochan [154].

In summary, a wide range of block copolymer nanostructures can be prepared via self-assembly. The careful use of block-selective solvents [73, 103], kinetic control $[133,154-156]$, or also the incorporation of complexation agents $[75,135,157,158]$, are some examples of how such morphological arrays can be expanded. While the highlighted examples were prepared as micelles in selective solvents, it is noteworthy that elaborate self- and directed assembly structures are also available through emulsification-evaporation [23] and solid film techniques [37]. It will be shown in subsequent sections that these already diverse morphological destinations reached through self-assembly can be expanded even more through crosslinking, sculpting, and coupling processes, or also via hierarchical assembly.

\subsection{Crosslinking: a road toward permanent structures}

Although block copolymer micelles typically have better stability [154] than micelles of traditional surfactants, they are still susceptible to dissociation, particularly if they are subjected to elevated temperatures, change of solvent, or dilution [159]. Meanwhile, crosslinking can convert block copolymer assemblies into permanent structures resistant to either disassembly or morphological transitions. Block copolymer micelles can accommodate selective crosslinking if they contain both responsive and non-responsive blocks to a particular crosslinking method. Early examples of micellar crosslinking were applied to the micellar core [160, 161], and the first group to stabilize block copolymer micelles by this strategy was that of Tuzar et al. [160]. In their first report, they used photochemical crosslinking to stabilize core-corona micelles of polystyrene-block-polybutadiene (PS- $b$-PB) in solvent mixtures selective for the PS block. This photocrosslinking strategy took advantage of the double bonds available within the collapsed PB core. Photocrosslinking was performed using UV irradiation and dibenzoyl peroxide as a photoinitiator. The crosslinking was applied here to stabilize the micelles for light scattering characterization, rather than as a synthetic strategy to prepare new materials as permanent structures. A limitation encountered was that the crosslinked micelles became insoluble in organic solvents once they were dried [160].

In the Liu lab, crosslinking was often accomplished by incorporating poly(2-cinnamoylethyl methacrylate) (PCEMA) as a copolymer block. PCEMA can readily undergo [2+2] cycloaddition upon UV irradiation at $274 \mathrm{~nm}$ [162]. This hydrophobic polymer tends to collapse in many solvents, often forming a solid micellar backbone. While the Liu group was the first to use this particular block as a photocrosslinkable unit within block copolymer micelles, the preparation and photocrosslinking of the PCEMA homopolymer was initially reported by Kato et al. [162]. Alt- hough crosslinking was employed earlier by researchers such as Tuzar et al. [160], Ishizu et al. [163-165], and by Wilson and coworkers [161], to stabilize block copolymer micelles for characterization purposes, the Liu group [46, 166] were the first to use micellar crosslinking as a synthetic strategy toward a diverse array of structures. This route initially provided us with nanospheres and star-polymers as permanent structures from their micellar precursors [46]. Additionally, these crosslinked structures were readily re-dispersed in solution. Since that report, Liu et al. applied this strategy to prepare a diverse array of dispersible permanent structures, including nanofibers [62], nanotubes [64, $65]$, solid spheres [35, 77, 167], hairy and partially or fully shaved hollow spheres [48], tadpoles [58, 59], imprinted tadpoles [60], macrocycles [61], and various other structures $[54,55]$.

While initial block copolymer micellar crosslinking approaches were applied to the micellar core, nanospheres with crosslinked shells have also been prepared. Wooley et al. [168, 169] developed at almost the same time as Liu and coworkers a shell-crosslinking synthetic approach. Various crosslinking strategies have been developed to stabilize block copolymer micelles, and are often chosen according to the functional groups available in the crosslinkable block. In addition to UV-visible crosslinking, other crosslinking strategies involving amidization [70], disulfide bridges [170], "click" chemistry [171], and organometallic crosslinkers [172] have been reported. While traditional crosslinking bridges served primarily to stabilize a block copolymer micelle, some recent reports have utilized crosslinking agents with inherent activity (such as catalytic [172] properties) allowing the crosslinker to serve a dual role, by both providing structural reinforcement and also imparting further functionality into the nanostructure [159]. Crosslinking has also provided an effective route toward elaborate structures, such as Janus micelles [173] by locking in the phase separation between two domains and allowing an assembly to retain its structure upon dispersal into solution or a different solvent $[173,174]$. Recent progress involving block copolymer micellar crosslinking has been highlighted in reviews by O'Reilly et al. [159], Read and Armes [175], and by van Nostrum [176].

\subsubsection{Microspheres and nanospheres}

Traditionally spherical block copolymers or micelle-like aggregates have been the most widely reported morphology [105]. In a block-selective solvent, these would typically consist of a core and a corona with a collapsed, insoluble core and a soluble corona. The nanospheres and microspheres prepared in the Liu lab were often derived from block copolymer micelles [47], which were subsequently crosslinked to "lock in" their structures. While a block copolymer micelle is in equilibrium between the aggregate and its unimer chains, nanospheres and microspheres are stable structures that resist dissociation into their unimer 
building blocks.

In addition to micellization, crosslinked block copolymer microspheres have also been prepared via emulsification [35]. In these cases, the emulsion droplets can serve as template to help direct the assembly toward the targeted nanostructure. The ability of amphiphilic block copolymers to behave as surfactants can prove particularly effective for achieving assembly at the interfaces between emulsion droplets and the continuous phase. Recently Liu et al. [55] prepared water-dispersible superparamagnetic microspheres bearing two types of surface chains. These particles resembled bumpy nano- and microspheres reported earlier by the Liu group [54], which were also prepared by emulsification. $\gamma-\mathrm{Fe}_{2} \mathrm{O}_{3}$ nanoparticles were coated with PAA- $b$-PCEMA, with the PAA facing the nanoparticles and the PCEMA block forming the surface, in a similar manner as applied toward singly coated cobalt nanoparticles [100]. These nanoparticles were dispersed into chloroform, along with PCEMA homopolymer, which would eventually form the cores of the bumpy spheres prepared as shown in Scheme 3. Photocrosslinking yielded permanent structures by binding the PCEMA blocks of the two surfactant copolymers to the PCEMA matrix of the core. The combination of emulsifica-

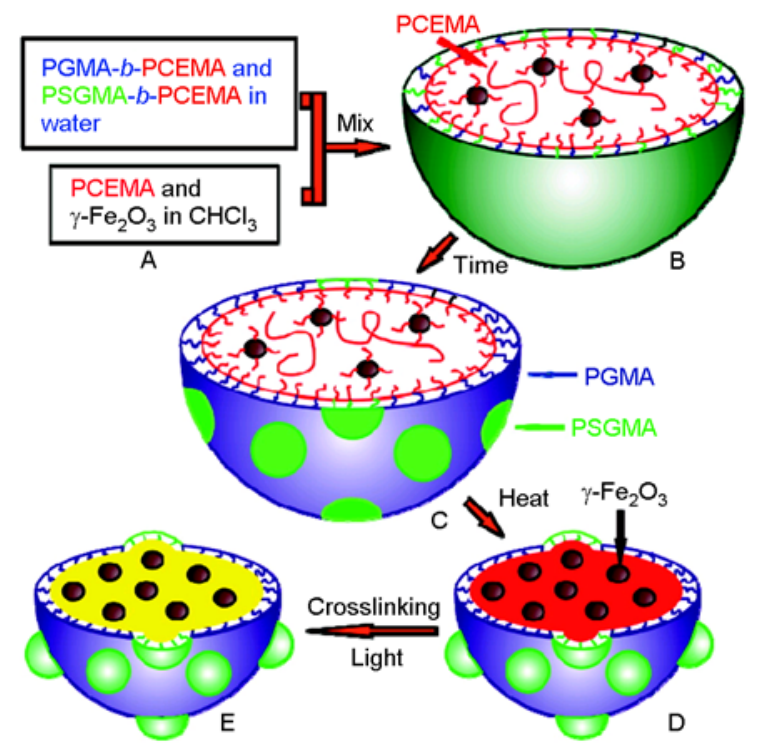

Scheme 3 Preparation of superparamagnetic microspheres with bumpy surfaces. An oil-in-water emulsion is prepared, with the oil phase consisting of PCEMA- $b$-PAA coated $\gamma-\mathrm{Fe}_{2} \mathrm{O}_{3}$ nanoparticles and PCEMA dispersed into chloroform $(\mathrm{A} \rightarrow \mathrm{B})$. Meanwhile, the surfactants PGMA- $b$-PCEMA and PSGMA- $b$-PCEMA dissolved in the aqueous phase stabilize the oil droplets. Once the droplet is stable, the incompatible PGMA and PSGMA chains form segregated domains on the droplet surface $(B \rightarrow C)$. Chloroform evaporation yields solid particles with the copolymer-coated $\gamma-\mathrm{Fe}_{2} \mathrm{O}_{3}$ nanoparticles mixed in a PCEMA matrix. As the emulsion droplet becomes smaller during the evaporation, the PSGMA domains (green) form bumps due to repulsions between the PSGMA carboxyl groups $(\mathrm{C} \rightarrow \mathrm{D})$. The structure is locked in by photocrosslinking the PCEMA domains, yielding permanent structures with the surfactant copolymers covalently bound to the core $(\mathrm{D} \rightarrow \mathrm{E})$ [55]. Reprinted with permission from Ref [55]. Copyright (2011) American Chemical Society. tion and evaporation also provides a powerful route towards a diverse range of architectures, which can often be made permanent through crosslinking [35]. An important concept behind the emulsification technique relies on block copolymers being either confined within an emulsion droplet or aggregating at the interface between the droplet and the continuous phase. Some examples may incorporate block copolymers both within the droplet and at the interface [177], with the latter interfacially confined block copolymers serving as surfactants and stabilizing the emulsion droplet [35, 177]. Whether a copolymer assembles at the droplet interface or is confined within a droplet can depend largely on the properties of the block copolymer. For example, an amphiphilic block copolymer can readily aggregate at the interface between the aqueous and the oil phases [177, 178]. Meanwhile, a block copolymer consisting of two hydrophobic blocks may be confined within the oil droplets of an oil-in-water emulsion $[179,180]$. The influence of spherical confinement encountered in the latter case can yield unique nanostructures that are not observed in bulk. Further details on the role of emulsification in directing block copolymer assembly are highlighted in a recent review [23].

The combination of the segregated carboxyl-bearing PSGMA domains on the emulsion and the magnetic properties provided by the embedded $\gamma-\mathrm{Fe}_{2} \mathrm{O}_{3}$ particles may allow potential applications in assays. The carboxyl-bearing PSGMA domains could bind to proteins, while these particles could also be captured by a magnet, and thus easily separated from an assay solution. Liu et al. [55] demonstrated this by binding bovine serum albumin (BSA) to the nanoparticles. In addition, anti-BSA could also bind with BSA that was immobilized onto the microsphere's surface.

Recently Liu et al. [83] prepared spherical micelles and nanospheres of the diblock copolymer poly[(2-ethylhexyl acrylate)-ran-(tert-butyl acrylate)]-block-poly(2-hydroxyethyl acrylate) (P(EXA- $r$-tBA)- $b$-PHEA) and various derivatives, which have improved friction reduction properties in an industrial base oil (Exxon Mobile EHC-45). To prepare most of these derivatives, the PHEA block was reacted with cinnamoyl chloride, thus replacing the PHEA units with crosslinkable poly(2-cinnamoyloxyethyl acrylate) (PCEA) units. In EHC-45 oil these copolymers formed micelles in which the PHEMA derivative block acted as the core while the P(EXA-r-tBA) block or its derivatives formed the corona. Meanwhile, nanospheres of these copolymers were also prepared by photo-crosslinking their PCEA cores in selective solvents for the $\mathrm{P}(\mathrm{EXA}-r$-tBA) derivative block. This crosslinking treatment was not performed in the EHC-45 oil, as it had photosensitive components.

The nanospheres and spherical micelles were then dispersed into the EHC-45 base oil to conduct friction reduction testing using a mini-traction machine. The ability of these block copolymer systems to reduce friction was compared to that of glyceryl monooleate (GMO) which is often 
used as an oil additive to help reduce friction between surfaces. The mini-traction machine used to measure the friction reductions of the block copolymer micelles and nanospheres on the oil included a stainless steel ball which was pressed against a stainless steel disk, which were both immersed into an oil reservoir (Figure 4). Both the ball and the disk were driven by motors, allowing them to rotate independently of one another at differing rotation speeds of $U_{\mathrm{b}}$ and $U_{\mathrm{d}}$, respectively. The entrainment speed $(U)$ represented the average of these two rotation speeds.

The degree of crosslinking was an important factor influencing the effectiveness of these nanostructures. Although the spherical micelles or nanoparticles required a crosslinkable core to aid friction reduction, the effectiveness diminished as the degree of crosslinking increased. Liu et al. attributed this trend to the PCEA core behaving as an elastomer at low crosslinking degrees. These elastomers could change their shape under physical stress without undergoing chemical decomposition. Apparently, the more heavily crosslinked cores were too rigid to readily change their shape under stress, reducing their effectiveness. However, systems lacking crosslinkable domains in their cores did not effectively reduce friction. In contrast, those bearing crosslinkable PCEA domains were effective, even if they had not

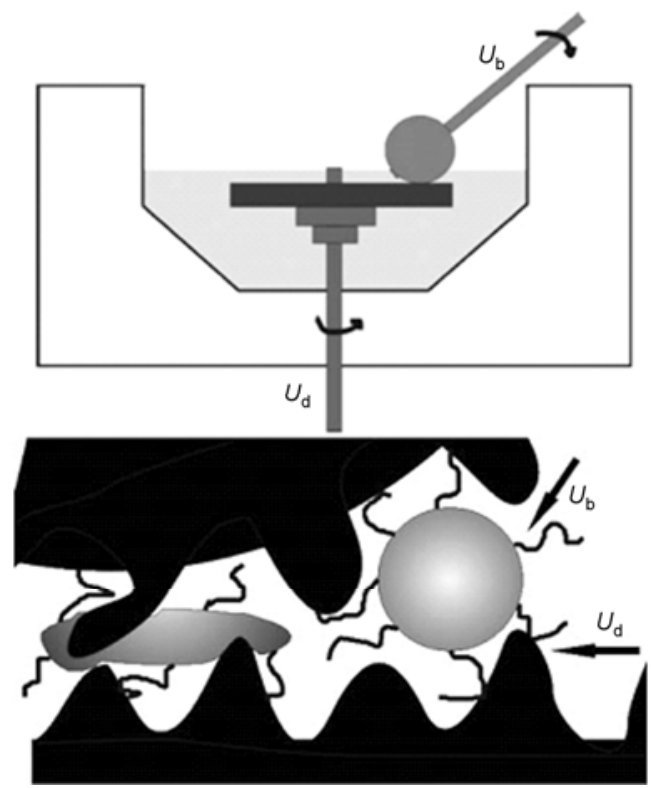

Figure 4 The mini-traction machine used to measure the effect of block copolymer nanoparticles on the friction between a stainless steel ball and a stainless steel disk that is immersed into an oil reservoir. The ball and the disc were able to rotate at different speeds ( $U_{\mathrm{b}}$ and $U_{\mathrm{d}}$, respectively) with respect to one another. The entrainment speed $(U)$ was defined as the average of these two speeds. The ball was pressed against the disk with a force of $35 \mathrm{~N}$, and measurements were taken at a temperature of $100{ }^{\circ} \mathrm{C}$ (top image). An expanded image of spherical micelles between the surfaces of the stainless steel ball and the stainless steel disk is also shown (bottom image). In this image, a lightly crosslinked particle is shown to undergo shape deformation, while retaining its structure. This particle reduces friction between the two metal surfaces by preventing their uneven protrusions from contacting each other [83]. Reprinted with permission from Ref. [83]. Copyright (2010) Taylor \& Francis Ltd. been photo-crosslinked. Apparently, the non-crosslinked PCEA core underwent a small degree of thermally-induced crosslinking during the friction reduction studies, which were conducted at $100{ }^{\circ} \mathrm{C}$. As this serves to demonstrate, control of the degree of crosslinking can be of critical importance for determining the properties of a permanent nanostructure. This case also provides an example of the applications that block copolymer nanostructures can provide, as the best performing systems in this study yielded better friction reduction than is provided by the conventional BMO additive [83]. While this example demonstrates the role that block copolymers can provide for friction reduction, the range of potential applications of block copolymers are diverse and have recently been highlighted in a review by Manners and coworkers [181].

\subsubsection{Block copolymer nanofibers}

Cylindrical block copolymer assemblies can be stabilized through selective crosslinking to yield nanofibers. These permanent nanostructures have diameters smaller than 100 $\mathrm{nm}$, and can either be prepared in the solid state from cylindrical block copolymers embedded in films, or in solution from cylindrical micelles. Block copolymer nanofibers [182] and nanotubes [98, 182] have been highlighted in recent reviews by Liu, although they will be briefly summarized here as well. The first reported block copolymer nanofibers were prepared in the Liu lab [62]. These nanofibers were prepared from the cylinder-forming diblock copolymer polystyrene-block-poly(2-cinnamoyloxyethyl methacrylate) (PS- $b$-PCEMA, $f_{\text {PCEMA }} \sim 26 \%$ ). In this initial report, the nanofibers were prepared from solid film precursors. The copolymer was first dissolved into toluene, which was then evaporated. Subsequent evaporation of the toluene and annealing of the resultant films yielded PCEMA cylinders that were surrounded by a PS matrix (Figure 5(a)). The PCEMA cylinders were photo-crosslinked by UV irradiation to lock in their structures. Following this, the films stirred in THF solution (Figure 5(b)), thus liberating the nanofibers from the films. These dispersed nanofibers consisted of crosslinked PCEMA cores surrounded by PS coronas, which

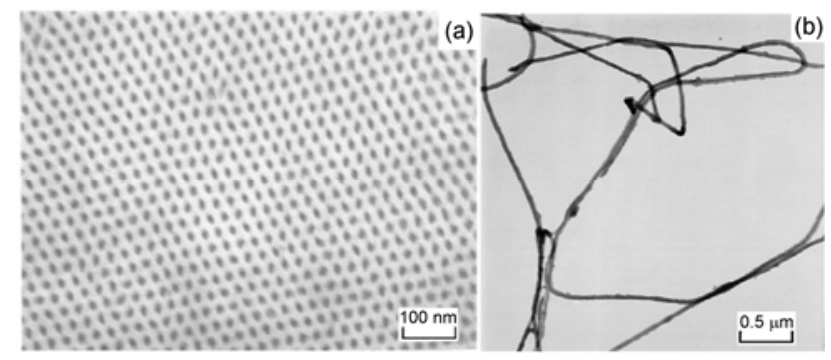

Figure 5 TEM images of a PS- $b$-PCEMA film, with hexagonally packed PCEMA cylinders (aligned perpendicular to the image) surrounded by a PS matrix. This image was recorded before crosslinking of the PCEMA domains (a). TEM image of crosslinked PS- $b$-PCEMA nanofibers dispersed into THF (b). The samples were stained with $\mathrm{OsO}_{4}$ [62]. Reprinted with permission from Ref [62]. Copyright (1996) American Chemical Society. 
aided their dispersal into organic solvents.

Shortly after this report, Liu et al. also prepared block copolymer nanofibers in solution from cylindrical micelles [63]. Like those prepared from solid films, these nanofibers were also prepared from a series of cylinder-forming PS- $b$-PCEMA copolymers. The copolymers were dispersed in a selective solvent for PS, and their micelles were then "locked in" by selectively photocrosslinking the PCEMA domains. These crosslinked micelles were subsequently precipitated from solution to yield the nanofibers.

Liu and coworkers performed physical studies of their block copolymer nanofibers, including fractionation, viscosity studies, as well as light-scattering and TEM analysis of their nanofibers $[63,182-186]$. Liu et al. noted that if the lengths of PS- $b$-PI nanofibers were not too long, their dilute solution behavior resembled that of polymer chains, and the viscosities of the samples decreased with decreasing shear rate [182]. The fractionation behavior of the nanofibers paralleled that of polymer chains, with longer nanofibers settling from solution more readily than shorter nanofibers $[183,184]$. The intrinsic viscosities of the nanofibers increased dramatically as the shear rate was decreased, suggesting that the nanofibers were aligned with the shearing direction [185]. However, the nanofiber chains experienced shear-thinning at a much lower shear rate [185] $\left(\sim 0.1 \mathrm{~s}^{-1}\right)$ than that typically observed among polymer chains, most likely due to the larger sizes of the nanofiber chains $\left(>10^{4}\right.$ $\mathrm{s}^{-1}$ ) [187]. Ultrasonication was used to break the nanofibers down into fractions of different lengths. This process induced cleavage of the nanofibers, and thus the lengths of the nanofibers decreased with increasing ultrasonication time. The lengths of the nanofibers could be assessed by TEM observation by calculating the average lengths of the nanofibers. In dilute solution, Liu and coworkers [185, 186] found that the nanofibers followed predictions of the Yamakawa-Fujii-Yoshizaki (YFY) theory, which was developed earlier to predict the behavior of worm-like polymer chains [188, 189]. In particular, when Liu and coworkers applied a simplified form of the YHY theory derived by Bohdanecky [190], they obtained reasonable persistence lengths and hydrodynamic diameters for the PS- $b$-PI nanofibers. Meanwhile, at higher concentrations, Liu and coworkers observed that block copolymer nanofibers formed a crystalline phase above a critical concentration. Onsager [191] and Flory [192] have predicted that polymer chains would form a liquid crystalline phase above a critical concentration, provided that the polymer's persistence length exceeded its hydrodynamic diameter by a factor of at least six. Liu and coworkers noted that PS- $b$-PCEMA nanofibers moved more slowly than polymer chains, due to their larger size. For example, PS- $b$-PCEMA nanofibers required mechanical shearing to induce liquid crystalline ordering.

Recently Li and Liu [193] utilized nanofibers to prepare porous films using a layer-by-layer approach. In particular, they prepared nanofibers bearing either pendant amines or carboxyl groups on their outer surfaces, utilizing electrostatic interactions between these nanofibers to prepare multilayered films. This approach is analogous to layer-by-layer [194, 195] film preparation normally performed using polyelectrolytes. The nanofibers were prepared from poly(2-cinnamoryloxyethyl methacrylate) ${ }_{175}$-block-poly(tert-butyl acrylate $)_{560}\left(\mathrm{PCEMA}_{175}-b-\mathrm{PtBA}_{560}\right)$ in the manner shown in Scheme 4 [193].

Depending on which nanofiber layer had been deposited first, the subsequent amine- and carboxyl-bearing nanofibers were deposited in alternating sequences via layerby-layer assembly. Because these layers were composed of block copolymer nanofibers, as opposed to block copolymers themselves, this layer-by-layer nanofiber deposition could also be considered as a hierarchical assembly, which was driven largely by electrostatic interactions between the carboxyl- and amine-bearing nanofibers. More examples of hierarchical assembly will be described in Section 3. These nanofiber-based films have potential application for separations. For example, they have been shown to respectively allow and block passage of PCEMA $_{100}-b-\mathrm{PtBA}_{290}$ and PCEMA $_{175}-b$-PtBA 560 nanospheres dispersed in methanol solution [193], with respective hydrodynamic diameters of 31 and $79 \mathrm{~nm}$.

\subsection{Structural etching: a road towards permanent sculpted structures}

Carving out void spaces from nanostructures can provide porous materials as supramolecular hosts $[64,76,196]$, for drug delivery [196], or for separations [48, 67, 78, 197-199]. Sculpted materials may also encapsulate transition metals [50, 52, 65, 200-203], thus acquiring catalytic [203] or magnetic properties [200, 202]. As with crosslinking, etch-

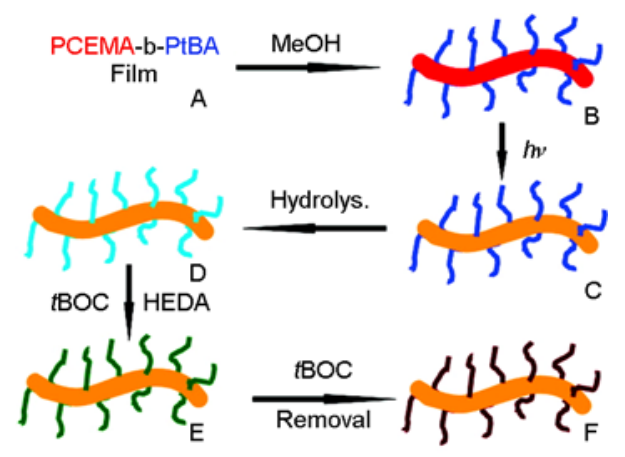

Scheme 4 To prepare the carboxyl- and amine-bearing nanofibers, PCEMA- $b$-PtBA was dispersed into methanol, yielding cylindrical micelles $(\mathrm{A} \rightarrow \mathrm{B})$. The PCEMA core was crosslinked by UV irradiation to yield nanofibers $(B \rightarrow C)$. The PtBA corona was subsequently converted to PAA via hydrolysis $(\mathrm{C} \rightarrow \mathrm{D})$, thus producing the carboxyl-bearing nanotubes (D). To prepare amine-bearing nanofibers, the PAA corona of the carboxyl-bearing nanofibers was reacted with $t$-BOC-HEDA $(\mathrm{D} \rightarrow \mathrm{E})$. The $t$-BOC group was then removed during a hydrolysis step $(\mathrm{E} \rightarrow \mathrm{F})$, which yielded the amine-bearing nanofibers (F) [193]. Reprinted with permission from Ref [193]. Copyright (2009) American Chemical Society. 
ing strategies can selectively target a specific copolymer block or nanostructure domain. Liu and coworkers were the first to apply sculpting techniques to block copolymer micelles, when they partially and fully removed polyisoprene (PI) domains from polyisoprene-block-poly(2-cinnamoylethyl methacrylate) micelles (PI- $b$-PCEMA) via ozonolysis [47, 48]. This approach yielded sculpted nanospheres from core-shell micelles [47], as well as hollow spheres from crosslinked vesicles whose PI domains were etched [48]. In the latter example, depending on how extensively the ozonolysis was performed, hairy, semi-shaved, or fully-shaved hollow spheres were obtained [48]. Initially, the external PI corona was selectively etched, while with extended ozonolysis treatment sculpted PI corona chains both outside and inside the crosslinked vesicles.

We also prepared thin films embedded with nanochannels from PtBA- $b$-PCEMA via sculpting techniques $[66,67]$. The blocks were carefully chosen to form films with hexagonally packed PtBA cylinders surrounded by a PCEMA matrix. The PCEMA matrix was crosslinked to lock in the film, and the PtBA domains were subsequently hydrolyzed, thus yielding nanochannels. Another benefit of PtBA hydrolysis is that the resultant void spaces are lined with the hydrolysis product PAA, which can bind to cations and thus allows transition metal loading [50, 52, 65, 68, 203]. While we were the first group to sculpt block copolymer micelles [47, 48], we were also among the first groups to sculpt block copolymer films [66, 67], as the first porous block copolymer films were reported in the late 1980 s by Lee and coworkers [204, 205]. Depending on the block copolymer composition, various sculpting methods are available, such as hydrolysis [206, 207], ozonolysis [47, 48, 76, 208, 209], and photolysis [210]. Selectively etched porous materials are described in recent reviews by Hillmyer and coworkers [211-213]. Broadly speaking, sculpting could also include strategies employing signal-responsive or biodegradable block copolymers that are respectively programmed to degrade at a target (such as a tumor) [214] due to external stimuli or through enzymatic or biological action in either the body or the natural environment $[215,216]$. The structures of permanent sculpted materials are diverse, including semiand fully-shaved spheres [48], hollow or porous spheres [48, $76,217]$, spheres with block-segregated patchy surfaces [218], nanotubes [64, 65, 202, 219], and etched films [68, 213].

\subsubsection{Capsules and hollow spheres}

Block copolymer capsules can be prepared through various approaches, including self-assembly [220], and through directed assembly via emulsification [57]. The former approach may yield vesicles, particularly if the volume fraction of the soluble block is low. In the latter approach, the emulsion droplet acts as a template to direct the assembly. Polymersomes, with aqueous cores, can be prepared by (W/O)/W double emulsions [221], where the copolymer is dissolved in the organic solvent and forms the vesicle wall as the or- ganic layer is evaporated. Alternatively, oil-filled vesicles can be prepared if the copolymer assembles at the interface between the two phases [57]. This may often involve an $\mathrm{ABC}$ triblock copolymer, where one of its blocks (usually the central B block) is insoluble in either the oil phase or the aqueous phase, so that the copolymer assembles around the oil droplet to eventually form the capsule wall. In some cases the shell-forming block may be crosslinked to stabilize the wall, yielding a capsule as a permanent structure.

Capsules can also be prepared through selective sculpting as well. In this case, a block copolymer may assemble in a block-selective solvent, to initially form spherical micelles. Subsequently the external block of the copolymer may be crosslinked, in order to stabilize that block and allow further chemical processing. The inner core block could then be selectively etched, to yield capsules through sculpting. Alternatively, a block copolymer may assemble around a sacrificial template, such as inorganic nanoparticles [222], which form the core and are removed at a later step to yield block copolymer-based capsules. In some cases, one of the copolymer blocks may be crosslinked to stabilize the copolymer and allow subsequent chemical processing. The template may then be removed, either by using a solvent that is selective for the template, or selectively decomposing the template to yield vesicles as permanent sculpted structures.

\subsubsection{Block copolymer nanotubes}

Nanotubes have drawn significant attention due to their wide ranging potential applications such as photonic [223-228] and electronic [229, 230] devices, catalysts [231, 232], and as porous host materials [233-236]. While carbon nanotubes [237-241] are among the most common, nanotubes have also been prepared from transition metals (including their oxides and alloys) [224, 226, 227, 242-244], peptides [245-252], lipids [253, 254], polymers [255], and block-copolymers. Block copolymer nanotubes can be prepared through self-assembly [256-258], or alternatively a combination of crosslinking and sculpting [64, 200]. The first reports of block copolymer nanotubes were by Eisenberg et al. [256, 257], who prepared nanotubes from polystyrene-block-poly(ethylene oxide) (PS- $b$-PEO) via selfassembly in selective solvent mixtures of $N, N$-dimethylformamide (DMF) and water, where DMF was a good solvent, and water was selective for the PEO block. The resultant micelles displayed various morphologies, including tubules, vesicles, porous spheres, spheres with protruding rods, and various other morphologies. These early nanotubes, or tubules, had enclosed cavities, rather than open ends, and their shapes varied significantly. In addition to linear tubules, also observed were ring shaped tubules, branched tubes, as well as complex interconnected tubules referred to as "plumber's nightmare" structures. These tubules arose through self-assembly as a bilayered structure, with the collapsed PS block forming the wall, and the coro- 
nal PEO chains extending into solution. The composition of the copolymer was an important factor in determining whether these nanotubes formed, as they were observed only when the volume ratio of the soluble PEO block was small.

Liu and coworkers developed a method to prepare nanotubes from $\mathrm{ABC}$ triblock copolymer nanofiber precursors [64, 65, 101, 102, 201, 202, 219]. The crosslinkable central block formed a shell in these nanotube precursors. The nanofiber cores were etched during a sculpting step, yielding nanotubes as permanent sculpted nanostructures. Meanwhile, the outermost corona block provided dispersibility to the nanotubes. As is the case with nanofibers, nanotubes can be prepared either from precursors in the solid state, or from micellar solutions. In their first report on block copolymer nanotubes, Stewart and Liu [64] prepared nanotubes from cylindrical micelles of polyisoprene ${ }_{130}$-block-poly(2-cinnamoylethyl methacrylate) ${ }_{130}$-block-poly(tert-butyl acrylate) ${ }_{800}$ $\left(\mathrm{PI}_{130}-b\right.$-PCEMA $\left.{ }_{130}-b-\mathrm{PtBA}_{800}\right)$ in selective solvents for the corona-forming PtBA block. Meanwhile the PCEMA and PI blocks were collapsed as the shell and core, respectively. After the PCEMA shells had been photocrosslinked to yield the precursorary nanofibers, the PI cores were subsequently etched out via ozonolysis, to yield the hollow nanotubes.

Shortly after this report, Liu et al. [200] also prepared nanotubes from solid films in a similar approach to that followed for nanofiber preparation. Through this method, the triblock copolymer polystyrene ${ }_{690}$-block-poly(2-cinnamoyloxyethyl methacrylate) $)_{170}$-block-poly(tert-butyl acrylate $)_{200}$ $\left(\mathrm{PS}_{690}-b\right.$-PCEMA $\mathrm{P}_{170}-b$-PtBA 200$)$ yielded hexagonally packed cylinders with PtBA cores and PCEMA shells in a PS matrix. The PCEMA shells were then photo-crosslinked, and the resultant nanofiber precursors were dispersed in a selective solvent for their PS chains. Subsequently, the PtBA cores were etched by cleaving the tert-butyl groups, thus converting the core into PAA and generating void spaces in the core (Scheme 5).

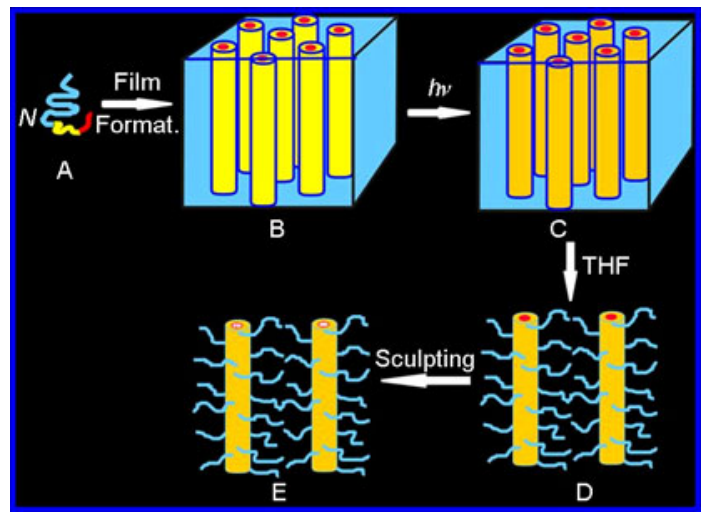

Scheme 5 Preparation of triblock copolymer $\left(\mathrm{PS}_{690}-b-\mathrm{PCEMA}_{170}-b\right.$ $\mathrm{PtBA}_{200}$ ) nanotubes from solid films. The copolymer is dissolved into toluene, and then cast as a film $(\mathrm{A} \rightarrow \mathrm{B})$. After annealing, the PCEMA shells are photocrosslinked to lock in their structure $(B \rightarrow C)$. The nanofibers are liberated from the film by dispersal into THF solution $(C \rightarrow D)$. Following this, the PtBA cores are converted into PAA by hydrolysis, yielding void spaces and thus forming the nanotubes $(D \rightarrow E)[200]$.
An interesting aspect of capsules and nanotubes is their ability to carry guests within their cavities. The $\mathrm{PS}_{690}-b$ $\mathrm{PCEMA}_{170}-b$-PtBA 200 nanotubes were subsequently impregnated with $\mathrm{Fe}_{2} \mathrm{O}_{3}$ nanoparticles in their PAA-lined hollow cores, which imparted the nanotubes with superparamagnetic properties. For example, when a magnetic field was applied to dispersions of nanotubes bearing $\mathrm{Fe}_{2} \mathrm{O}_{3}$ nanoparticles, which were subsequently set as a gel, TEM analysis of the $\mathrm{Fe}_{2} \mathrm{O}_{3}$ nanoparticle-bearing nanotubes imbedded in the gel showed that they had become aligned with the magnetic field. Since this report, water-dispersible block copolymer nanotubes incorporating Pd nanoparticles [201] as well as Pd/Ni hybrid nanoparticles [202] have been prepared. Block copolymer nanotubes have also been prepared by other researchers, including Winnik, Manners and their coworkers [259, 260], by Meier et al. [261], as well as recent examples by Feng et al. [258], Pan et al. [262], and Jia et al. [263]. For drug delivery, the cylindrical shape of the nanotubes could be advantageous [264-266], as cylindrical micelles have relative larger internal volumes and better flexibility than their spherical counterparts.

\subsubsection{Cleavable block copolymers}

A closely related strategy to etching a sacrificial block itself is the use of a cleavable block junction placed between two blocks. The degradation of these block junctions can be triggered by various stimuli, such as light [267, 268], reducing agents [269-272], or heat [271, 272], thus cleaving the attached block from the copolymer. Some examples of cleavable block junctions include redox-cleavable disulfide [269, 270, 273, 274], photo-cleavable ortho-nitrobenzyl $(O N B)$ [267, 268], thermally- and photo-cleavable anthracene photodimers [271, 272], acid-cleavable trityl ether [275, 276] or cyclic ortho ester [277] groups. In addition, cleavable ABC [278] or ABA [279, 280] triblock copolymers bearing sacrificial central B blocks have been reported. The use of the cleavage-inducing stimuli after the copolymers have aggregated into micelles can cause the micelles to shed their corona layer. This technique thus has significant potential for the triggered release of drugs from block copolymer micelles [270]. An exciting aspect of the block junction cleavage approach is its potential efficiency, as typically only one unit needs to be cleaved per polymer chain [281].

Kataoka and coworkers [269] synthesized PEG- $S_{2}-$ $\mathrm{P}[\mathrm{Asp}(\mathrm{DET})]$ copolymers, where P[ASP(DET)] corresponds to poly(aspartamide) copolymers that bear a $N$-(2-aminoethyl)2-aminoethyl groups in their side chain and $S_{2}$ corresponds to the disulfide block junction attached to the poly(ethylene glycol) block. In aqueous solution, micelles of PEG- $S_{2}-$ $\mathrm{P}[\mathrm{Asp}(\mathrm{DET})]$ were loaded with plasmid DNA (pDNA) cargoes (Figure 6(a,b)). Exposure of the micelles to reducing agents such as dithiothreitol, resulted in cleavage of the PEG chains from the micelles. In addition, the disulfide linkage also underwent eventual cleavage when these mi- 
(a)

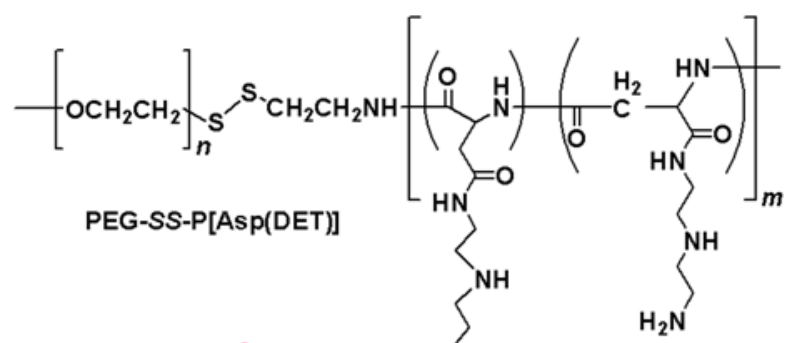

(b)

(c)
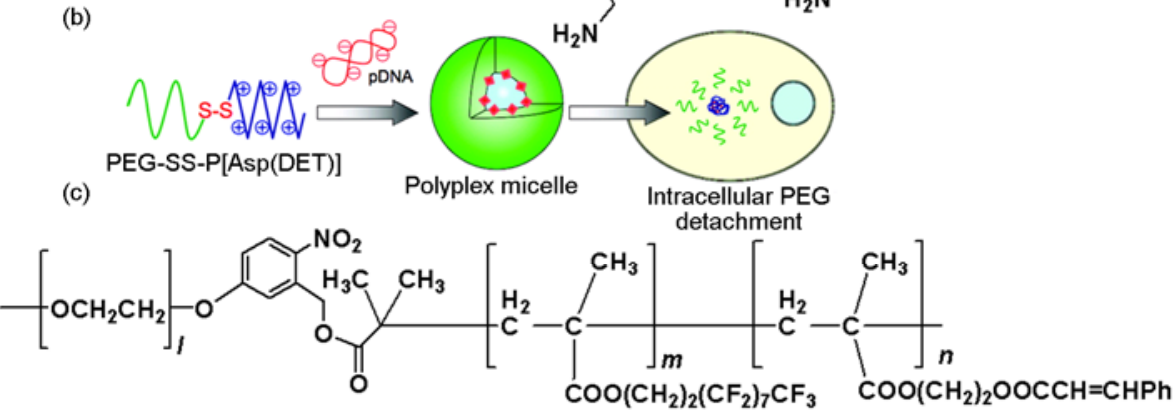

PEO-ONB-PFOEMA-b-PCEMA

(d)

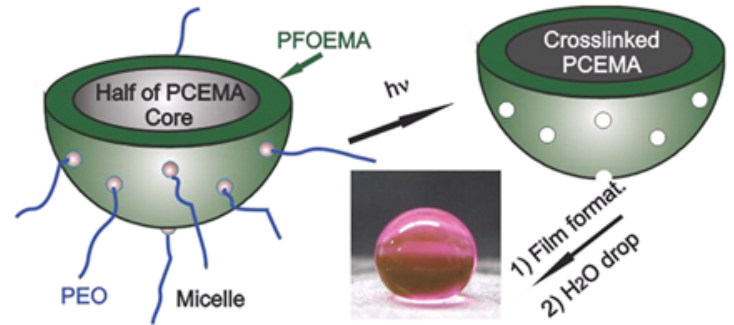

Figure 6 Selected examples of assemblies based on cleavable block copolymers. PEG- $S_{2}$-P[Asp(DET)] (a) was used to prepare polyplex micelles with pDNA, which shed their coronal PEG chains upon exposure to reducing agents or after uptake by HELA cells (b). Assemblies based on the photo-cleavable block copolymer PEO-ONB-PFOEMA- $b$-PCEMA (c). As shown in (d), this copolymer yielded core-shell-corona micelles in selective solvents for the PEO corona chains. Upon photolysis, the PCEMA core became crosslinked, while the PEO chains were cleaved. Due to the exposure of the fluorinated PFOEMA chains, these PEO-cleft particles could be used to prepare films with self-cleaning properties. Images (a-b) reprinted with permission from Ref. [269]. Copyright (2008) American Chemical Society. Images (c-d) reprinted with permission from Ref. [290]. Copyright (2012) American Chemical Society.

celles were internalized by HELA cells, and the authors found that micelles bearing a disulfide linkage exhibited significantly higher gene transfection efficiency than micelles that lacked disulfide linkages [269].

As mentioned above, block copolymers bearing photocleavable $O N B$ linkages have been used by Kang and Moon [267] to prepare porous films, and Schumer et al. [268] have used a one-pot ATRP-CuAAC click reaction to synthesize $O N B$-linked block copolymers. Meier and coworkers [282] prepared degradable vesicles and micelles from block copolymers bearing $O N B$ junctions. Photoresponsive polymers, including photocleavable block copolymers, have been highlighted in reviews by Theato et al. [281, 283], Schumers et al. [284], as well as by Zhao and coworkers $[285,286]$. The use of $O N B$ units and their derivatives in various polymer systems has recently been reviewed by Zhao and coworkers [287], and Theato [281] has highlighted block copolymer systems bearing various types of photo-cleavable junctions. Photo-cleavable $O N B$ linkages have also recently been used by the Liu group. In aqueous
THF solutions poly(ethylene oxide) ${ }_{113}-O N B$-poly[2-(perfluorooctyl)ethyl methacrylate) ${ }_{12}$-block-poly(2-cinnamoyloxyethyl methacrylate $)_{25}\left(\mathrm{PEO}_{113}-O N B\right.$-PFOEMA $\left.{ }_{12}-b-\mathrm{PCEMA}_{25}\right)$ yielded core-shell-corona micelles in which the PEO, PFOEMA, and PCEMA blocks formed the corona, shell, and core domains respectively (Figure 6(c-d)). When these micelles were irradiated under a UV lamp, they exhibited two responses. The PCEMA-based cores became crosslinked, while the corona-forming PEO chains were cleaved from the micelles as the $O N B$ junctions underwent a Norrish II rearrangement [288]. After the cleavage of the PEO corona chains, the remaining particles became less soluble due to the loss of their coronal chains and they aggregated together to help minimize their exposure to the solvent. An interesting and potentially useful feature of these PEO-cleft particles was the exposure of their fluorinated PFOEMA block. Since fluorinated materials have low surface energies, they can exhibit self-cleaning properties due to their ability to repel both water and oil [289]. When films were prepared from both non-photolyzed micelles and photolyzed particles, 
the contact angles of water and dichloromethane droplets increased dramatically for the droplets that were placed on films prepared from the latter particles bearing exposed PFOEMA domains, rendering them superhydrophobic and also oil-repellent.

\subsection{A special case: architectural polymers}

Although many block copolymer-based nanostructures are multi-chain aggregates, sometimes these nanostructures are derived from individual block copolymer chains. A recent example of architectural polymers prepared in solution from diblock copolymers includes tadpole structures [59, 60]. These structures can be prepared from individual AB diblock copolymer chains in solvent mixtures that are selective for the A block. The insoluble B block forms a globule (the tadpole "head"), while the soluble A block stretches out to form the polymer tail. Meanwhile, Liu and coworkers have prepared pompon-coil-pompon structures and pearlring macrocycles [61] from ABA triblock copolymers in solvent mixtures that are selective for the central block. Illustrations of these structures are depicted in Scheme 6. In these systems, the collapsed terminal A block forms globules at the ends of the polymer chain. In dilute solution, the collapsed globules at the ends of the chain may merge together to form a unimolecular macrocycle, with the fused globule forming the pearl, and the B block forming the ring [61]. Architectural polymers have been highlighted in recent reviews by Hadjichristidis [94], Tezuka [291-293], Hirao [294], Liu [95] and their coworkers.

\subsubsection{Molecularly imprinted tadpoles}

Tadpole-shaped architectures were prepared from amphiphilic block copolymers [58, 59]. While block copolymer tadpole structures were prepared by the Liu group,

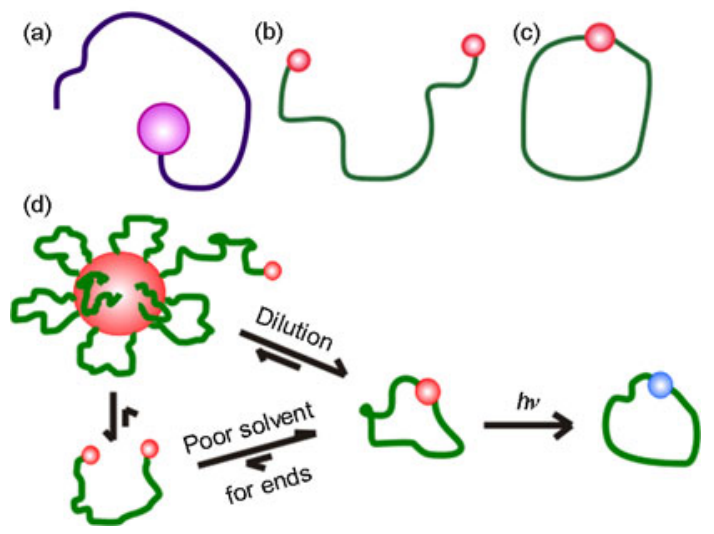

Scheme 6 Illustrated structures of various architectural polymers, including tadpoles (a), pompon-coil-pompon structures (b) and pearl ring macrocycles (c). The insoluble block forms a collapsed globule, while the soluble block stretches into the solvent. The formation of pompon-coilpompon and pearl-ring macrocycles through the dilution of their micellar precursors is shown in (d). Subsequent crosslinking can lock in the structure, as is shown for the pearl-ring macrocycle in this scheme. some examples of these structures have also been synthesized by Hawker et al. [295] and by Li and coworkers [296]. Typically, block copolymer tadpole structures incorporate a soluble block as the tail, and a collapsed block forming the tadpole head. Recently Liu et al. [60] expanded on this, using the tadpole-shaped polymers as platforms for chiral molecular imprinting. These tadpoles thus belong to the family of molecularly imprinted polymers (MIPs) [297, 298]. Applications of MIPs are diverse, including separations (as stationary phases) [299], chiral resolution [299, 300], catalysis [301], drug delivery, and also for detection of poisons [302], drugs [303], or explosives [304, 305]. MIPs are normally crosslinked to ensure a good fit between the polymer matrix and the template. Among the architectural single-chain tadpoles, the crosslinking was intramolecular rather than intermolecular. In contrast to typical MIPs, the imprinted tadpoles were templated in the presence of pre-formed block copolymers, rather performing a polymerization in the presence of the template. The sizes of the tadpoles, consisting of an individual block copolymer chain, are considerably smaller than typical MIP particles. This small size could be advantageous in that a higher proportion of the binding sites would be available near the surface, rather than deeply buried in the polymer, and it could allow fast analyte release and rebinding kinetics.

The tadpoles were prepared through a dilution technique (Scheme 7). The block copolymer poly(tert-butyl acrylate)block-poly[(2-cinnamoyloxyethyl methacrylate)-ran-[2-(2'carboxybenzoyloxy)ethyl methacrylate]] (PtBA- $b$-P(CEMA$r$-CA), was dispersed into a selective solvent for the PtBA block to yield micelles with $\mathrm{P}(\mathrm{CEMA}-r$-CA) forming the core and PtBA forming the corona. The micelles were equilibrated with a chiral organic template, which became embedded within the $\mathrm{P}(\mathrm{CEMA}-r$-CA $)$ micelle core. The micelles were then diluted by gradually pumping them into a larger reservoir containing a similar solvent (and also template). This dilution induced the micelles to dissociate into their unimer copolymer chains or tadpoles, with the collapsed P(CEMA-r-CA) block forming the head and PtBA chain forming the tail. The insoluble tadpole heads were photocrosslinked, thus yielding permanent structures while also locking in the imprinting process.

\section{Hierarchical and coupled nanostructures}

While most topics discussed so far have involved strategies to prepare assembly structures from block copolymer building blocks, such assemblies can themselves form building blocks toward higher ordered systems. This may involve assembly of either similar or different nanostructures into the higher ordered system. While hierarchical assembly is analogous to self-assembly, the coupling technique described here involves an active linking together of 

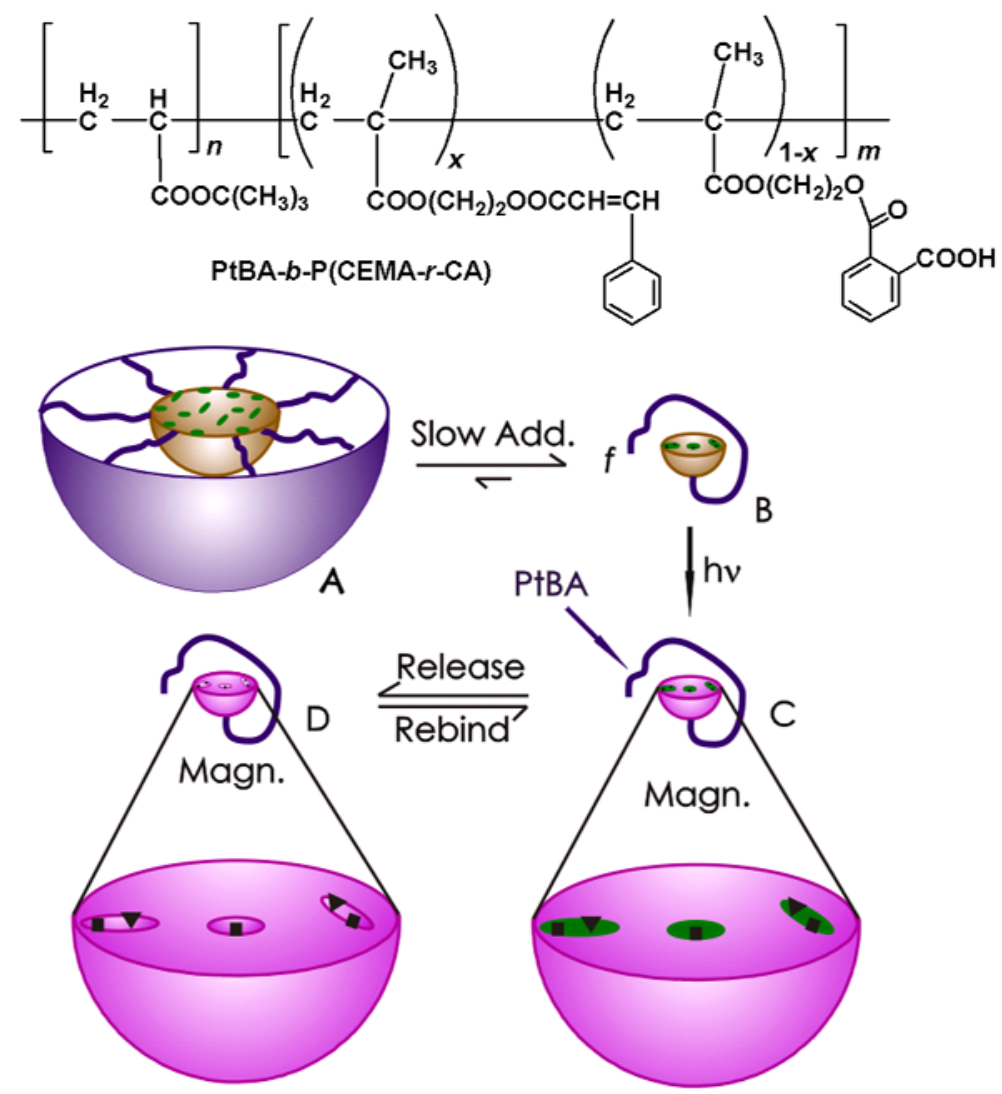

Scheme 7 Preparation of chirally imprinted tadpoles via dilution and photocrosslinking. In the presence of a template a micellar solution of PtBA- $b$-P(CEMA- $r$-CA) (structure shown at the top) is gradually diluted and dissociates into its single-chain unimers by slow-addition into a solvent reser$\operatorname{voir}(A \rightarrow B)$. These unimers are photocrosslinked in the reservoir to yield permanent tadpole structures $(B \rightarrow C)$. The template can be gradually removed by dialysis to yield imprinted tadpoles that are free to bind to matching target molecules $(C \rightarrow D)$ [60].

two (or more) nanostructures to obtain a more complex structure. Typically the coupling process involves the combination of a smaller number of nanostructure units than is encountered among hierarchical assembly, and coupling normally requires more active input from the designer (often involving covalent binding of different nanostructures). The coupling process may sometimes precede hierarchical assembly. Either individual nanostructures or also coupled nanostructures can form building blocks for hierarchical assembly.

\subsection{Hierarchical assembly structures}

As described here, hierarchical structures are those whose building blocks are of a higher order than block copolymers themselves. With this in mind, hierarchical systems are prepared through a "double assembly" process, where nanostructures (such as micelles, permanent structures or permanent sculpted structures) serve as building blocks for hierarchical structures. The afore-mentioned nanostructures are themselves composed of block copolymer building blocks in an initial assembly step preceding the hierarchical assembly. Hierarchical assemblies could also encompass assemblies occurring through an even greater number of assembly steps. For example, hierarchical structures formed from a double assembly could subsequently act as building blocks for a higher order structure, through a triple assembly. Owing to the higher order of hierarchical systems, they can frequently yield structures with extended dimensions [306].

\subsubsection{Nanoropes and composite fibers}

Recently the Liu group prepared nanoropes and composite nanofibers as hierarchical structures [307]. The nanoropes are composed of two different types of nanofiber building blocks which are bundled together. The nanofibers were derivatives of PCEMA- $b$-PtBA and PtBA- $b$-PCEMA- $b$ PDMAEMA, that were adorned with carboxyl and amine groups, respectively, and PDMAEMA corresponds to poly $(N, N$-dimethylaminoethyl methacrylate). The nanofibers were prepared by dispersing the block copolymers in solvents that were selectively poor for the PCEMA blocks. 
After the PCEMA crosslinking treatment, nanofibers bearing amine or DMAEMA groups were obtained from the triblock copolymer. The carboxyl groups were obtained through the hydrolysis of the PtBA coronal chains of the diblock copolymer nanofibers, yielding PAA coronal chains.

Once the carboxyl-bearing and amine-bearing nanofibers were prepared, they were mixed together by slowly adding a dilute carboxyl-bearing nanofiber solution into an aminebearing nanofiber solution. The carboxyl-bearing nanofibers needed to be surrounded by an excess of amine-bearing nanofibers to ensure that the nanofibers were dispersed into solution. The degree of crosslinking among the carboxyl-bearing nanofibers was approximately $32 \%$, but much lower among the amine-bearing nanofibers, at either $0 \%$ or $3 \%$. Such a low degree of crosslinking was necessary to prevent precipitation of the latter amine-bearing nanofibers. In addition, the structures of these cylindrical micelles were not really locked in at such low crosslinking degrees, and thus the amine-bearing nanofibers were technically not true nanofibers, which have permanent structures. The aminebearing nanofibers formed bundles wrapped around the carboxyl-bearing nanofibers, with multiple amine-bearing nanofibers surrounding a given carboxyl-bearing nanofiber (Figure 7(a). The mixture was then thermally annealed to allow the amine-bearing PDMAEMA chains of the aminebearing nanofibers to migrate so that they could face the PAA groups of the central carboxyl-bearing nanofiber, thus helping to further bind the structure together. Meanwhile, the PtBA groups of the amine-bearing nanofibers shuffled themselves so that they primarily faced the exterior of the structure. This position shuffling converted the nanoropes into composite nanofibers, and the repositioning of the PtBA domains of the external surface of the nanoropes helped to disperse the hierarchical nanoropes in solution.

The duration of the thermal annealing process had a significant effect on the resultant structures. Immediately after the two sets of nanofibers were mixed they apparently formed bundled fibers or ropes, with amine-forming nanofibers forming bridges between different nanoropes, or dangled from the nanoropes. As thermal annealing treatment was applied, the dangling amine-bearing nanoropes gradually merged with the nanoropes, to yield smooth composite nanofibers. This was supported by TEM evidence (Figure 7(b-d)) as well as dynamic light scattering (DLS) experiments. The latter DLS measurements showed the hydrodynamic radii $\left(R_{\mathrm{h}}\right)$ of the mixture of the amine- and carboxyl-bearing nanofibers, increased dramatically upon mixing to $790 \mathrm{~nm}$ (from an $R_{\mathrm{h}}$ of $423 \mathrm{~nm}$ recorded for the carboxyl-bearing nanofibers before mixing) but decreased gradually during thermal annealing treatment to $490 \mathrm{~nm}$ after two weeks of thermal annealing. The dramatic increase in $R_{\mathrm{h}}$ could be attributed to the amine-bearing nanofibers forming bridges between different nanoropes. These bridges eventually merged with individual nanoropes with anneal- ing treatment, as evidenced by the gradual decrease in $R_{\mathrm{h}}$. With this in mind, the thermal annealing process served to direct the assembly, and provided energy needed to convert the kinetic product into the thermodynamically favored composite nanofibers.

\subsubsection{Controlled Hierarchical Assembly}

The examples described above may be considered as hierarchical analogs of self-assembly, or double assembly. However, directed assembly can also occur at the hierarchical level, as controlled or programmed hierarchical assembly. For example, the interfacial assembly of triblock copolymer micelle-like aggregates (MAs) into either ribbon-cage shaped or flower-shaped hierarchical superaggregates [49], as well as the assembly of block copolymer-coated nanoparticles into linear chain-like structures [100]. In the former example emulsion droplets served as templates to direct the hierarchical assembly, with the MAs assembling into superaggregates at the droplet surfaces [49]. Among the polymer-coated cobalt chains (Figure 8), magnetic dipole-dipole interactions caused the cobalt nanoparticles to assemble into their chainlike hierarchical structures [100].

The dipolar cobalt nanoparticles forming the hierarchical chains were coated with $\mathrm{PCEMA}_{30}-b-\mathrm{PAA}_{4}$ or with $\mathrm{PtBA}_{290^{-}}$ $b$-PCEMA ${ }_{100}$ [100]. The cobalt nanoparticles were prepared through the high temperature decomposition of $\mathrm{Co}_{2}(\mathrm{CO})_{8}$ in dichlorobenzene in the presence of $\mathrm{PCEMA}_{30}-b-\mathrm{PAA}_{4}$ as a surfactant and trioctylphosphine oxide as a cosurfactant. This produced cobalt nanoparticles coated by PCEMA ${ }_{30^{-}}$ $b$-PAA 4 , with the PAA domain coordinated to the cobalt-filled core, and the PCEMA domain forming the outer layer. These nanoparticles could be further coated with $\mathrm{PtBA}_{290}-b$-PCEMA 100 . To accomplish this, the PCEMA ${ }_{30^{-}}$ $b$-PAA ${ }_{4}$ coated cobalt nanoparticles were redispersed into chloroform, a good solvent for both blocks. Another copolymer, $\mathrm{PtBA}_{290}-b$-PCEMA 100 , was then added to this dispersion. Following this, methanol was added, causing the PCEMA block to collapse. The PCEMA block of PtBA $290^{-}$ $b$-PCEMA ${ }_{100}$ aggregated along the surface of the cobalt nanoparticles, which was occupied by the PCEMA domain from the initial $\mathrm{PCEMA}_{30}-b-\mathrm{PAA}_{4}$ coating. The PCEMA blocks of these two copolymers were compatible with one another, and thus the cobalt nanoparticles were coated with the two copolymers. These latter particles were thus doubly coated nanoparticles, while the particles coated with only PCEMA $_{30}-b$-PAA 4 were essentially singly coated cobalt nanoparticles. The PtBA block on the doubly coated particles extended into the solution to form the corona, and helped disperse the nanoparticles into various organic solvents. These coated nanoparticles were structurally locked by photocrosslinking the PCEMA domains.

Due to magnetic dipole-dipole interactions between the cobalt nanoparticles, they formed linear chains and, to a lesser extent, branched chains. In addition to stabilizing the 
(a)

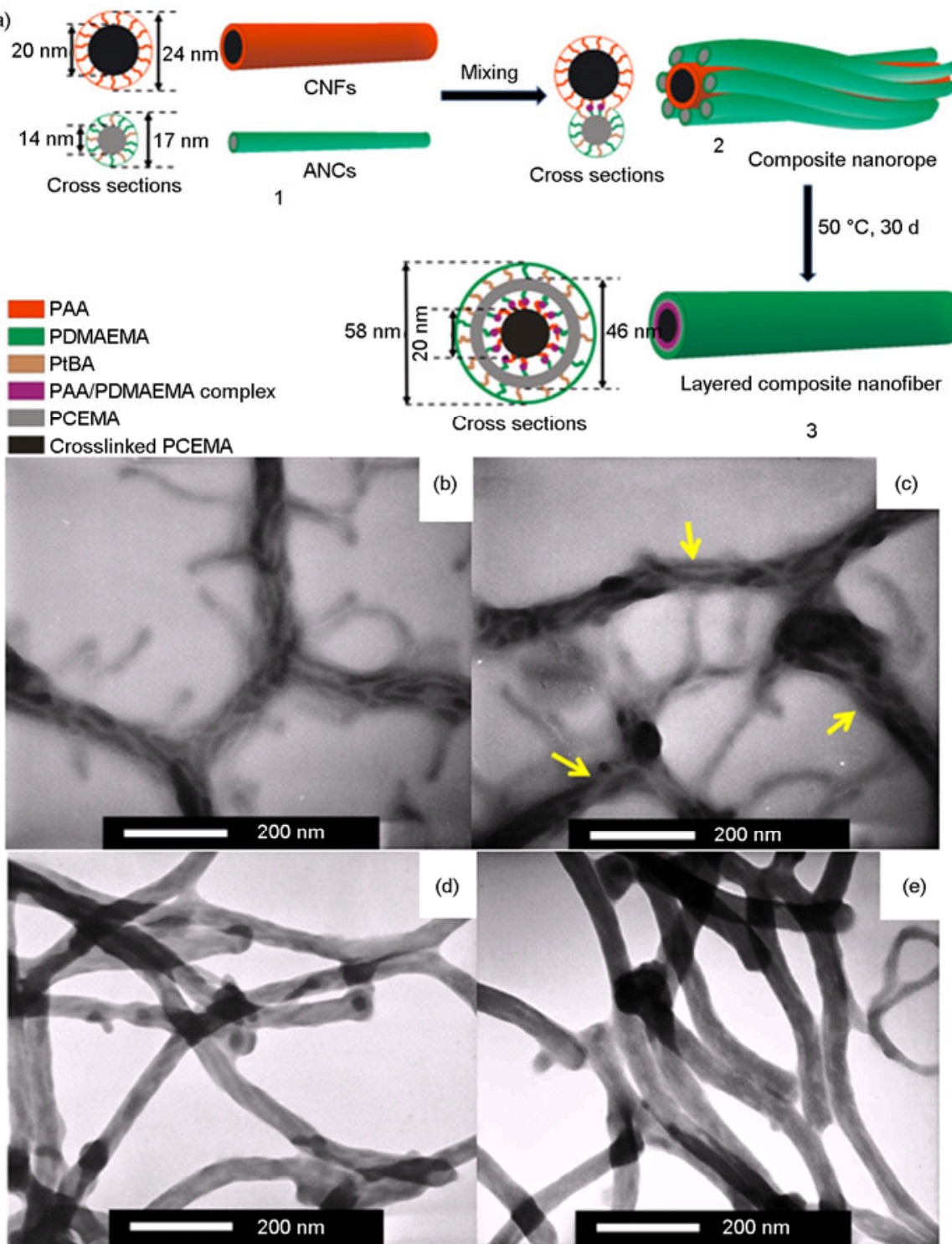

Figure 7 Illustration (a) showing the preparation of nanoropes as hierarchical structures from carboxyl-bearing nanofibers that were bundled with amine-bearing nanofibers. Initially the amine-bearing nanofibers form bundles surrounding a carboxyl-bearing nanofiber in solution to form a nanorope $(1 \rightarrow 2)$ following slow addition of a dilute solution of carboxyl-bearing nanofibers to a solution of amine-bearing nanofibers. The mixtures were then thermally annealed. During this process, the amine-bearing PDMAEMA chains of the amine-bearing nanofibers shuffled themselves so that they could have better expose to the PAA groups of the central carboxyl-bearing nanofiber $(2 \rightarrow 3)$, yielding composite nanofibers [307]. TEM images of mixtures of amineand carboxyl-bearing nanofibers immediately after mixing (b) and after $12 \mathrm{~h} \mathrm{(c),} 2$ days (d), and 14 days (e) of thermal annealing at $50{ }^{\circ} \mathrm{C}$. The ratio of carboxyl- to amine-bearing nanofibers was 1:5, the degrees of crosslinking among the amine- and carboxyl-bearing nanofibers were $3 \%$ and $32 \%$, respectively. The samples were sprayed with $\mathrm{OsO}_{4}$. The arrows in image (c) show amine-bearing nanofibers that had begun to merge with the nanoropes. Reprinted from Ref. [307] by permission of The Royal Society of Chemistry (RSC).

individual nanoparticle structures, the structures of these chains were also locked in by the photocrosslinking step. Thus, the assembly of the cobalt nanoparticles into chains was directed by the magnetic dipole-dipole interactions, and locked in by photocrosslinking. These nanoparticle chains could be considered as coupled nanostructures due in part to the noncovalent magnetic dipole-dipole interactions between the nanoparticles, and to the covalent crosslinking of their PCEMA shells following the photolysis step, which yielded the permanent chains. The magnetic properties of the cobalt nanoparticles chains were retained after the crosslinking step.

These permanent structures obtained by crosslinking the doubly coated cobalt nanoparticle chains, which were also precursors to permanent sculpted structures. Liu et al. [100] etched the cobalt cores using acidic media, such as $\mathrm{HCl}$ solution, hence dissolving the cores. The remaining $\mathrm{PtBA}_{290^{-}}$ $b$-PCEMA 100 coating retained its dispersibility in chloroform and chainlike shape, with empty cavities at the sites formerly occupied by the cobalt cores. This demonstrated that cobalt etching from the nanoparticle chains could generate porous, solvent-dispersible polymer nanofibers. 


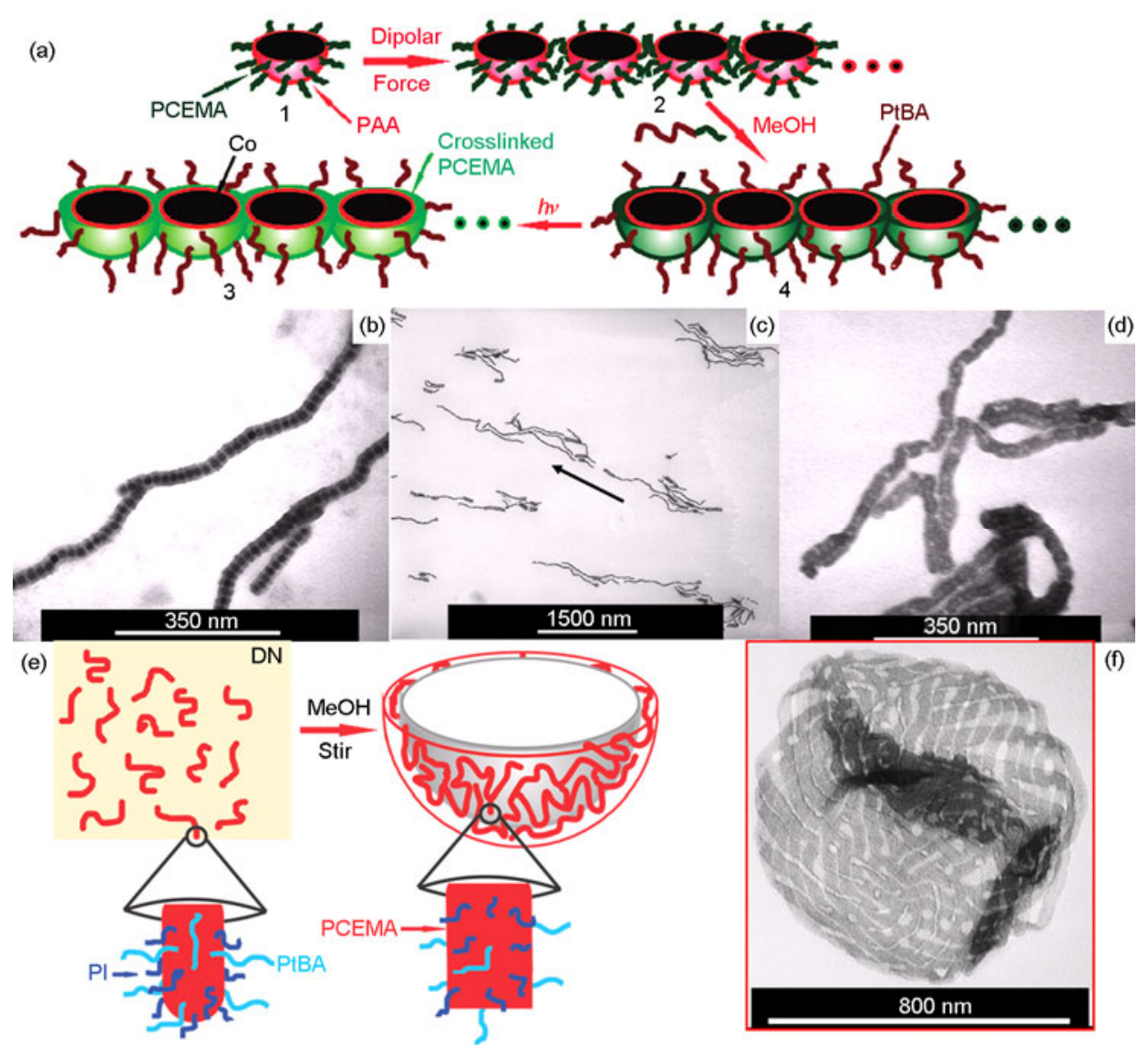

Figure 8 Illustration showing the preparation of cobalt nanoparticles (image a) that were coated with $\mathrm{PCEMA}_{30}-b$-PAA 4 , aligned into linear chains by magnetic dipole-dipole interactions $(1 \rightarrow 2)$, and coated with $\mathrm{PtBA}_{290}-b$-PCEMA $100(2 \rightarrow 3)$. The PCEMA domains were then photocrosslinked $(3 \rightarrow 4)$ to yield permanent chains of cobalt. TEM image of doubly-coated and crosslinked cobalt nanoparticle chains after they were dissolved into dichloromethane, dripped onto a carbon coated copper TEM grid adjacent to a $0.47 \mathrm{~T}$ magnet, and the solvent evaporated (images $\mathrm{b}$ and $\mathrm{c}$ ). The arrow indicates the direction of the magnetic field (image c). TEM image of porous fibers left behind after cobalt cores of the doubly coated and crosslinked nanoparticles chains were dissolved into $\mathrm{HCl}$ (image d). These permanent sculpted fibers retained the dispersive properties of their cobalt-containing precursors [100]. Illustration of the assembly (e) of cylindrical $\mathrm{PI}_{110}-b$-PCEMA $150^{-} b$-PtBA 320 MAs at the surface of a DN emulsion droplet, where methanol forms the continuous phase. A TEM image of a hierarchical ribbon-cage assembly structure. Images a-d reprinted with permission from Ref. [100]. Copyright (2009) American Chemical Society. Image e reprinted from Ref. [23] with permission from Elsevier. Copyright (2011) Elsevier.

Flower-like and Ribbon-cage shaped hierarchical assemblies arose from the fusion of polyisoprene ${ }_{110}$-blockpoly(2-cinnamoyloxyethyl methacrylate) ${ }_{150}$-block-poly(tertbutyl acrylate $)_{320}\left(\mathrm{PI}_{110}-b\right.$-PCEMA $\left.150-b-\mathrm{PtBA}_{320}\right)$ MAs at the surfaces of emulsion droplets [49]. Either cylindrical or spherical MAs were initially prepared from the triblock copolymer. Cylindrical MAs were prepared by dispersing $\mathrm{PI}_{110}-b$-PCEMA $150-b$-PtBA 320 into decahydronaphthalene (DN) and gently heating the mixture. Alternatively, spherical MAs were obtained by dissolving the copolymer into dichloromethane and then adding DN. The dichloromethane was subsequently removed by bubbling nitrogen into the mixture. In either case, PCEMA formed the micellar core, and PI and PtBA formed the mixed corona. Either the cylindrical or spherical aggregates were the building blocks for the subsequent hierarchical assembly. This hierarchical assembly was achieved through emulsification. These emulsions were prepared by adding methanol to DN dispersions of the cylindrical or spherical aggregates and vigor- ously stirring these immiscible solvents, yielding DN emulsion suspended in the continuous methanol phase. Depending whether flower-like or ribbon-like superaggregates were the target structure, the emulsion was heated at either 22 or $52{ }^{\circ} \mathrm{C}$, respectively. While $\mathrm{DN}$ was selective for PI and PtBA, only PtBA was soluble in methanol. The MAs gathered along the droplet surfaces, with the PCEMA domain localized at the interface, and mainly the PI and (to a lesser extent) PtBA chains projecting outward into the DN continuous phase and PtBA extending inward into the methanol droplets. The PCEMA domains had apparently flattened somewhat to provide a more uniform droplet coating. The emulsion droplets thus served as a template for the hierarchical assembly.

\subsection{Coupled nanostructures}

An example of coupled nanostructure preparation was reported by Liu et al. [101] involving the coupling of nano- 
tubes to nanospheres composed of PS- $b$-PCEMA- $b$-PAA and PCEMA- $b$-PAA, respectively. The PS- $b$-PCEMA- $b$ PAA nanotubes were prepared by a combination of crosslinking and etching from the solid film approach in a similar general manner to that described in the section highlighting nanotubes, yielding nanotubes with PAA lining the etched core, PCEMA forming the shell, and PS forming the corona. The nanotubes were coupled to PCEMA- $b$-PAA nanospheres bearing crosslinked PCEMA cores and PAA coronas.

The nanotubes and the nanospheres were coupled together covalently. To accomplish this, an excess of PAES$b$-PS- $b$-PAES (where PAES corresponds to poly[4-(2aminoethyl)styrene]) spacing chains were attached via amidization to the PAA carboxyl groups that were exposed at the ends of the nanotubes. The free terminal PAES blocks of these grafted spacers were then reacted with the carboxyl groups of the PAA corona of the PCEMA- $b$-PAA nanospheres following a similar approach, thus linking the nanotubes with the nanospheres. The PS- $b$-PCEMA- $b$-PAA nanotubes, with their PS corona, were dispersible in organic solvents. Meanwhile, the PCEMA- $b$-PAA nanospheres, having a PAA corona, were water-dispersible. Therefore, a hydrophobic nanotube and hydrophilic nanosphere were coupled together, providing a hierarchical analog of a surfactant molecule, or a "supersurfactant" [101]. The nanotube acted as the supersurfactant tail, while the nanosphere behaved as the head group. While the covalent binding of the nanotubes to the nanospheres was a coupling process,

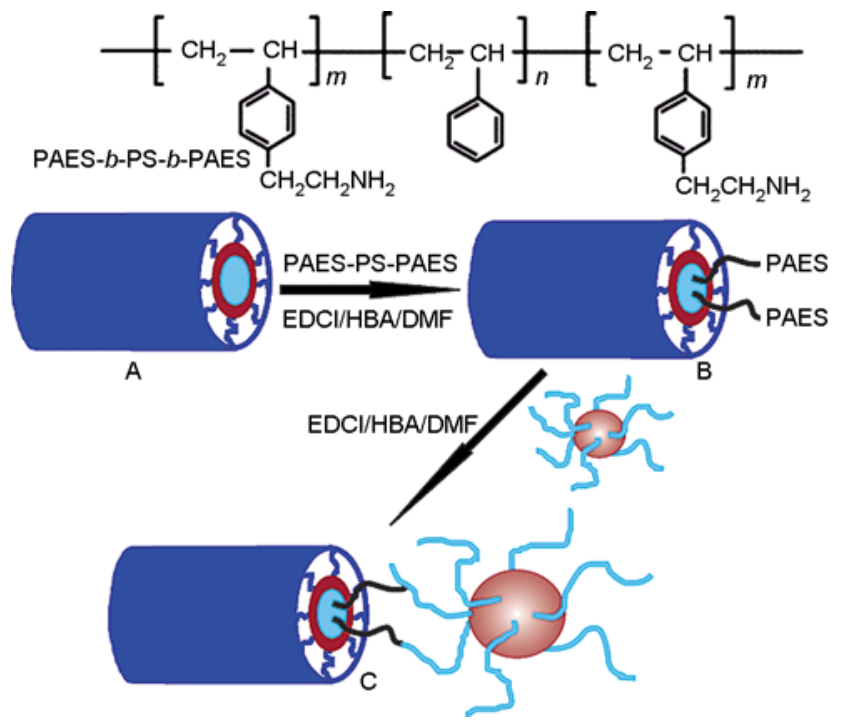

Scheme 8 Coupling of PS- $b$-PCEMA- $b$-PAA nanotubes to PCEMA- $b$-PAA nanospheres. The PAES- $b$-PS- $b$-PAES spacer was attached to the ends of the PS- $b$-PCEMA- $b$-PAA nanotubes by amidization, which linked one of the terminal PAES blocks to the PAA carboxyl groups at the end of the nanotubes $(\mathrm{A} \rightarrow \mathrm{B})$. Subsequent amidization was carried out between the free PAES block of the grafted spacers to the PAA domain in the corona of the PCEMA- $b$-PAA nanospheres $(B \rightarrow C)$ [101]. Reprinted with permission from Ref. [101]. Copyright (2003) American Chemical Society. the aggregation of these supersurfactants to form a "supermicelle" would be an example of hierarchical assembly Scheme 8 [101]. Chen and coworkers [308] have also reported hierarchical supermicelle micelle formation from block copolymer Janus particles, due to the anisotropic nature of the Janus particles.

A similar covalent coupling strategy was also employed by Liu et al. [102] to couple together nanotubes composed of poly(glyceryl methacrylate)-block-poly[(2-cinnamoyloxyethyl methacrylate)-ran-(2-hydroxyethyl methacrylate)]block-poly(tert-butyl acrylate) (PGMA- $b$-P(CEMA- $r$ HEMA)- $b$-PtBA) and PS- $b$-PCEMA- $b$-PAA. These coupled nanotubes could be considered as hierarchical analogs of block copolymers, with each nanotube analogous to a copolymer block. Interestingly, these coupled nanotubes also subsequently underwent hierarchical assembly in solution, aggregating to yield hierarchical analogs of block copolymer micelles. Meanwhile, in thin films, these coupled nanotubes underwent "nanotube segregation" in an analogous manner to block segregation [102]. Another exciting feature of both the coupled nanotubes and the hybrid nanosphere and nanotube systems is their potential to carry mixed cargoes, which may yield applications as drug delivery systems. Hierarchical analogs of block copolymer micelles have also been prepared by Manners, Winnik, and their coworkers through the sequential epitaxial growth of different block copolymers bearing crystalline cores [309].

\section{Conclusions}

This review has attempted to highlight the diverse variety of block copolymer nanostructures that have been prepared by the Liu group following an array of pathways including self-assembly, directed assembly, hierarchical assembly, and coupling between nanostructures. Selective crosslinking and etching have also played key roles in these pathways, yielding permanent structures, sculpted structures, and permanent sculpted structures. In some cases the permanent and the permanent sculpted structures were destinations themselves, while other times they provided stable precursors towards assemblies of even greater complexity.

While block copolymers are the building blocks of the assemblies described here, these assemblies can subsequently serve as building blocks for hierarchical assembly, thus yielding structures of even higher order. While the building blocks may be identical to one another, hierarchical assembly can alternatively occur between different types of nanostructure building blocks. The hierarchical assembly described here is sometimes also called double assembly. However, one may also employ this approach to prepare assemblies with even higher order, such as triple or even quadruple assemblies.

While diblock copolymers have frequently been used for these assemblies, triblock copolymers have been employed 
as well. The greater morphological diversity among block terpolymers is exciting, particularly when combined with the array of assembly pathways highlighted in this article. While development of triblock copolymer (and those with higher block numbers) assemblies have been somewhat limited in the past, this area has seen rapid growth in recent years $[7,10]$.

A high degree of control can be achieved over the assembly of block copolymers bearing crystalline blocks [310, 311]. This was demonstrated by Manners and coworkers [311-313], who prepared cylindrical micelles with highly controlled lengths via crystallization-driven self-assembly of block copolymers bearing a crystalline core-forming block. The unique structures afforded by crystalline and liquid-crystalline [314] block copolymers ensures that they will continue to have a bright future.

While the target structures prepared by Liu and coworkers are interesting in their own right, some of these assemblies can yield practical applications as well. Some have potential as drug delivery systems [196], water purification [78], for chiral resolution [60], and friction reduction among lubrication oils [83]. Considering the diversity of block copolymer assemblies available, combined with the diverse array of assembly pathways employed by our group, the variety of block copolymer assemblies available may be limited only by the imagination.

Guojun Liu wishes to thank NSERC of Canada for a Tier 1 Canada Research Chair and for funding.

1 Khandpur AK, Foerster S, Bates FS, Hamley IW, Ryan AJ, Bras W, Almdal K, Mortensen K. Polyisoprene-polystyrene diblock copolymer phase diagram near the order-disorder transition. Macromolecules, 1995, 28(26): 8796-8806

2 Bates FS, Fredrickson GH. Block copolymers-designer soft materials. Phys Today, 1999, 52(2): 32-38

3 Leibler L. Theory of microphase separation in block copolymers. Macromolecules, 1980, 13(6): 1602-1617

4 Matsen MW, Bates FS. Unifying weak- and strong-segregation block copolymer theories. Macromolecules, 1996, 29(4): 1091-1098

5 Bates FS, Fredrickson GH. Block copolymer thermodynamics: Theory and experiment. Annu Rev Phys Chem, 1990, 41: 525-557

6 Matsen MW, Bates FS. Origins of complex self-assembly in block copolymers. Macromolecules, 1996, 29(23): 7641-7644

7 Hadjichristidis N, Iatrou H, Pitsikalis M, Pispas S, Avgeropoulos A. Linear and non-linear triblock terpolymers. Synthesis, self-assembly in selective solvents and in bulk. Prog Polym Sci, 2005, 30(7): 725782

8 Moughton AO, Hillmyer MA, Lodge TP. Multicompartment block polymer micelles. Macromolecules, 2012, 45(1): 2-19

9 Schacher F, Reinicke S, Walther A, Schmalz H, Müller AHE. New amphiphilic nanostructures based on block terpolymers made by anionic polymerization. NATO Sci Peace Secur Ser A Chem Biol, 2009, 3: 167-186

10 Wyman IW, Liu G. Micellar structures of linear triblock terpolymers: Three blocks but many possibilities. Polymer, 2013, 54(8): 19501978

11 Olsen BD, Segalman RA. Self-assembly of rod-coil block copolymers. Mater Sci Eng, R, 2008, 62(2): 37-66

12 Whitesides GM, Grzybowski B. Self-assembly at all scales. Science,
2002, 295(5564): 2418-2421

13 Abetz V, Simon PFW. Phase behaviour and morphologies of block copolymers. Adv Polym Sci, 2005, 189: 125-212

14 Morkved TL, Lu M, Urbas AM, Ehrichs EE, Jaeger HM, Mansky P, Russell TP. Local control of microdomain orientation in diblock copolymer thin films with electric fields. Science, 1996, 273(5277): 931-933

15 Boker A, Knoll A, Elbs H, Abetz V, Müller AHE, Krausch G. Large scale domain alignment of a block copolymer from solution using electric fields. Macromolecules, 2002, 35(4): 1319-1325

16 Böker A: Control of block copolymer microdomain orientation from solution using electric fields: Governing parameters and mechanisms. In Nanostructured soft matter; Zvelindovsky A V, Ed.; Springer: Dordrecht, 2007; pp 199-229

17 Kim H, Jeong SM, Park JW. Electrical switching between vesicles and micelles via redox-responsive self-assembly of amphiphilic rod-coils. J Am Chem Soc, 2011, 133(14): 5206-5209

18 Lee SJ, Park MJ. Morphological manipulation of ionic block copolymer micelles using an electric field. Langmuir, 2010, 26(23): 17827-17830

19 Giacomelli FC, da Silveira NP, Nallet F, Cernoch P, Steinhart M, Stepanek P. Cubic to hexagonal phase transition induced by electric field. Macromolecules, 2010, 43(9): 4261-4267

20 Majewski PW, Gopinadhan M, Jang WS, Lutkenhaus JL, Osuji CO. Anisotropic ionic conductivity in block copolymer membranes by magnetic field alignment. J Am Chem Soc, 2010, 132(49): 1751617522

21 McCulloch B, Portale G, Bras W, Segalman RA. Increased order-disorder transition temperature for a rod-coil block copolymer in the presence of a magnetic field. Macromolecules, 2011, 44(19): 7503-7507

22 Tao Y, Zohar H, Olsen BD, Segalman RA. Hierarchical nanostructure control in rod-coil block copolymers with magnetic fields. Nano Lett, 2007, 7(9): 2742-2746

23 Wyman I, Njikang G, Liu G. When emulsification meets selfassembly: The role of emulsification in directing block copolymer assembly Prog Polym Sci, 2011, 36(9): 1152-1183

24 Cheng JY, Ross CA, Smith HI, Thomas EL. Templated selfassembly of block copolymers: Top-down helps bottom-up. Adv Mater, 2006, 18(19): 2505-2521

25 Shum HC, Weitz DA. Multicompartment polymersome gel for encapsulation. Soft Matter, 2011, 7(19): 8762-8765

26 Wang CW, Sinton D, Moffitt MG. Flow-directed block copolymer micelle morphologies via microfluidic self-assembly. J Am Chem Soc, 2011, 133(46): 18853-18864

27 Lin Y, Daga VK, Anderson ER, Gido SP, Watkins JJ. Nanoparticledriven assembly of block copolymers: A simple route to ordered hybrid materials. J Am Chem Soc, 2011, 133(17): 6513-6516

28 Bae KH, Choi SH, Park SY, Lee Y, Park TG. Thermosensitive pluronic micelles stabilized by shell cross-linking with gold nanoparticles. Langmuir, 2006, 22(14): 6380-6384

29 Cai Y, Aubrecht KB, Grubbs RB. Thermally induced changes in amphiphilicity drive reversible restructuring of assemblies of abc triblock copolymers with statistical polyether blocks. J Am Chem Soc, 2011, 133(4): 1058-1065

30 Schmelz J, Karg M, Hellweg T, Schmalz H. General pathway toward crystalline-core micelles with tunable morphology and corona segregation. ACS Nano, 2011, 5(12): 9523-9534

31 Darling SB. Directing the self-assembly of block copolymers. Prog Polym Sci, 2007, 32(10): 1152-1204

32 Segalman RA. Patterning with block copolymer thin films. Mater Sci Eng R, 2005, 48(6): 191-226

33 Herr DJC. Directed block copolymer self-assembly for nanoelectronics fabrication. J Mater Res, 2011, 26(2): 122-139

34 Zhang J, Yu X, Yang P, Peng J, Luo C, Huang W, Yanchun Han Y. Microphase separation of block copolymer thin films. Macromol Rapid Commun, 2010, 31(7): 591-608

35 Lu Z, Liu G, Liu F. Block copolymer microspheres containing intricate nanometer-sized segregation patterns. Macromolecules, 
2001, 34(25): 8814-8817

36 Yabu H, Higuchi T, Ijiro K, Shimomura M. Spontaneous formation of polymer nanoparticles by good-solvent evaporation as a nonequilibrium process. Chaos, 2005, 15(4): 047505-047507

37 Hamley IW. Ordering in thin films of block copolymers: Fundamentals to potential applications. Prog Polym Sci, 2009, 34(11): 1161-1210

38 Tsarkova L, Sevink GJA, Krausch G. Nanopattern evolution in block copolymer films: Experiment, simulations and challenges. $A d v$ Polym Sci, 2010, 227: 33-73

39 Albert JNL, Epps TH. Self-assembly of block copolymer thin films. Mater Today, 2010, 13(6): 24-33

40 Fasolka MJ, Mayes AM. Block copolymer thin films: Physics and applications. Annual Review of Materials Research, 2001, 31(1): 323-355

41 Green PF, Limary R. Block copolymer thin films: Pattern formation and phase behavior. Adv Colloid Interface Sci, 2001, 94(1-3): 53-81

42 Riess G. Micellization of block copolymers Prog Polym Sci, 2003, 28(7): 1107-1170

43 Zhang L, Eisenberg A. Multiple morphologies of "crew-cut" aggregates of polystyrene- $b$-poly(acrylic acid) block copolymers. Science, 1995, 268(5218): 1728-1731

44 Zhang L, Eisenberg A. Multiple morphologies and characteristics of "crew-cut" micelle-like aggregates of polystyrene- $b$-poly(acrylic acid) diblock copolymers in aqueous solutions. J Am Chem Soc, 1996, 118(13): 3168-3181

45 Walther A, Muller AHE. Janus particles: Synthesis, self-assembly, physical properties, and applications. Chem Rev, 2013, http:// dx.doi.org/10.1021/cr300089t

46 Guo A, Liu G, Tao J. Star polymers and nanospheres from crosslinkable diblock copolymers. Macromolecules, 1996, 29(7): 24872493

47 Tao J, Liu G, Ding J, Yang M. Cross-linked nanospheres of poly(2-cinnamoylethyl methacrylate) with immediately attached surface functional groups. Macromolecules, 1997, 30(14): 40844089

48 Ding J, Liu G. Hairy, semi-shaved, and fully shaved hollow nanospheres from polyisoprene-block-poly(2-cinnamoylethyl methacrylate). Chem Mater, 1998, 10(2): 537-542

49 Hu J, Liu G, Nijkang G. Hierarchical interfacial assembly of abc triblock copolymer. J Am Chem Soc, 2008, 130(11): 3236-3237

50 Lu Z, Liu G, Liu F. Water-dispersible porous polyisoprene-blockpoly(acrylic acid) microspheres. J Appl Polym Sci, 2003, 90(10): 2785-2793

51 Liu G, Yang H, Zhou J, Law S-J, Jiang Q, Yang G. Preparation of magnetic microspheres from water-in-oil emulsion stabilized by block copolymer dispersant. Biomacromolecules, 2005, 6(3): 12801288

52 Underhill RS, Liu G. Triblock nanospheres and their use as templates for inorganic nanoparticle preparation. Chem Mater, 2000, 12(8): 2082-2091

53 Li Z, Liu G, Law S-J, Sells T. Water-soluble fluorescent diblock nanospheres. Biomacromolecules, 2002, 3(5): 984-990

54 Zheng R, Liu G, Yan X. Polymer nano- and microspheres with bumpy and chain-segregated surfaces. J Am Chem Soc, 2005, 127(44): 15358-15359

55 Zhou Z, Liu G, Hong L. Water-dispersible superparamagnetic microspheres adorned with two types of surface chains. Biomacromolecules, 2011, 12(3): 813-823

56 Ding J, Liu G. Polyisoprene-block-poly(2-cinnamoylethyl methacrylate) vesicles and their aggregates. Macromolecules, 1997, 30(3): 655657

57 Zheng R, Liu G. Water-dispersible oil-filled abc triblock copolymer vesicles and nanocapsules. Macromolecules, 2007, 40(14): 51165121

58 Tao J, Liu G. Polystyrene-block-poly(2-cinnamoylethyl methacrylate) tadpole molecules. Macromolecules, 1997, 30(8): 2408-2411

59 Njikang G, Liu G, Curda SA. Tadpoles from the intramolecular photo-cross-linking of diblock copolymers. Macromolecules, 2008,
41(15): 5697-5702

60 Njikang G, Liu G, Hong L. Chiral imprinting of diblock copolymer single-chain particles. Langmuir, 2011, 27(11): 7176-7184

61 Hu J, Zheng R, Wang J, Hong L, Liu G. Macrocycles from the photochemical coupling of preassociated terminal blocks of block copolymers. Macromolecules, 2009, 42(13): 4638-4645

62 Liu G, Qiao L, Guo A. Diblock copolymer nanofibers. Macromolecules, 1996, 29(16): 5508-5510

63 Tao J, Stewart S, Liu G, Yang M. Star and cylindrical micelles of polystyrene-block-poly(2-cinnamoylethyl methacrylate) in cyclopentane. Macromolecules, 1997, 30(9): 2738-2745

64 Stewart S, Liu G. Block copolymer nanotubes. Angew Chem Int Ed, 2000, 39(2): 340-344

65 Yan X, Liu F, Li Z, Liu G. Poly(acrylic acid)-lined nanotubes of poly(butyl methacrylate)-block-poly(2-cinnamoyloxyethyl methacrylate). Macromolecules, 2001, 34(26): 9112-9116

66 Liu G, Ding J, Guo A, Herfort M, Bazett-Jones D. Potential skin layers for membranes with tunable nanochannels. Macromolecules, 1997, 30(6): 1851-1853

67 Liu G, Ding J. Diblock thin films with densely hexagonally packed nanochannels. Adv Mater, 1998, 10(1): 69-71

68 Liu G, Ding J, Hashimoto T, Kimishima K, Winnik FM, Nigam S. Thin films with densely, regularly packed nanochannels: Preparation, characterization, and applications. Chem Mater, 1999, 11(8): 22332240

69 Liu G, Ding J, Stewart S. Preparation and properties of nanoporous triblock copolymer membranes. Angew Chem Int Ed, 1999, 38(6): 835-838

70 Dou H, Hong L, Liu G. Miktoarm star copolymers from the chemical stitching of associating block copolymers. Macromolecules, 2010, 43(10): 4629-4637

71 Hu J, Njikang G, Liu G. Twisted abc triblock copolymer cylinders with segregated a and c coronal chains. Macromolecules, 2008, 41(21): 7993-7999

72 Dupont J, Liu G, Niihara K-i, Kimoto R, Jinnai H. Self-assembled abc triblock copolymer double and triple helices. Angew Chem Int Ed, 2009, 48(33): 6144-6147

73 Dou H, Liu G, Dupont J, Hong L. Triblock terpolymer helices self-assembled under special solvation conditions. Soft Matter, 2010, 6(17): 4214-4222

74 Liu G, Hu N, Xu X, Yao H. Cross-linked polymer brushes. 1. Synthesis of poly[ $p$-(vinyloxy)ethyl cinnamate]- $b$-poly (isobutylvinyl ether). Macromolecules, 1994, 27(14): 3892-3895

75 Dupont J, Liu G. Abc triblock copolymer hamburger-like micelles, segmented cylinders, and janus particles. Soft Matter, 2010, 6(15): 3654-3661

76 Stewart S, Liu G. Hollow nanospheres from polyisoprene-blockpoly(2-cinnamoylethyl methacrylate)-block-poly(tert-butyl acrylate). Chem Mater, 1999, 11(4): 1048-1054

77 Henselwood F, Liu G. Water-soluble nanospheres of poly(2cinnamoylethyl methacrylate)-block-poly(acrylic acid). Macromolecules, 1997, 30(3): 488-493

78 Henselwood F, Wang G, Liu G. Removal of perylene from water using block copolymer nanospheres or micelles. J Appl Polym Sci, 1998, 70(2): 397-408

79 Lu Z, Liu G, Phillips H, Hill JM, Chang J, Kydd RA. Palladium nanoparticle catalyst prepared in poly(acrylic acid)-lined channels of diblock copolymer microspheres. Nano Lett, 2001, 1(12): 683-687

80 Xiong D, Liu G, Zhang J, Duncan S. Bifunctional core-shell-corona particles for amphiphobic coatings. Chem Mater, 2011, 23(11): 2810-2820

81 Xiong D, Liu G, Hong L, Duncan EJS. Superamphiphobic diblock copolymer coatings. Chem Mater, 2011, 23(19): 4357-4366

82 Zheng R, Wang J, Liu G, Jao T-C. Lubricant-oil-dispersible stainlesssteel-binding block copolymer nanoaggregates and nanospheres. Macromolecules, 2007, 40(21): 7601-7608

83 Zheng R, Liu G, Devlin M, Hux K, Jao T-c. Friction reduction of lubricant base oil by micelles and crosslinked micelles of block copolymers. Tribol Trans, 2010, 53(1): 97-107 
84 Liu G. Functional crosslinked nanostructures from block copolymers. Mater Sci Eng C, 1999, 10(1-2): 159-164

85 Whitesides GM, Boncheva M. Beyond molecules: Self-assembly of mesoscopic and macroscopic components. Proc Natl Acad Sci, USA, 2002, 99(8): 4769-4774

86 Matsen MW, Schick M. Self-assembly of block copolymers. Curr Opin Colloid Interface Sci, 1996, 1(3): 329-336

87 Matsen MW. Self-assembly of block copolymers in thin films. Curr Opin Colloid Interface Sci, 1998, 3(1): 40-47

88 Giacomelli C, Borsali R: Disordered phase and self-organization of block copolymer systems. In Soft matter characterization; Borsali R, Pecora R, Eds.; Springer Science + Business Media, LLC: New York, 2008; pp 133-189.

89 Giacomelli C, Schmidt V, Aissou K, Borsali R. Block copolymer systems: From single chain to self-assembled nanostructures. Langmuir, 2010, 26(20): 15734-15744

90 Grzelczak M, Vermant J, Furst EM, Liz-Marzan LM. Directed self-assembly of nanoparticles. ACS Nano, 2010, 4(7): 3591-3605

91 Tyrrell ZL, Shen Y, Radosz M. Fabrication of micellar nanoparticles for drug delivery through the self-assembly of block copolymers. Prog Polym Sci, 2010, 35(9): 1128-1143

92 Harada A, Kataoka K. Supramolecular assemblies of block copolymers in aqueous media as nanocontainers relevant to biological applications. Prog Polym Sci, 2006, 31(11): 949-982

93 Hirao A, Hayashi M, Loykulnant S, Sugiyama K, Ryu SW, Haraguchi N, Matsuo A, Higashihara T. Precise syntheses of chain-multifunctionalized polymers, star-branched polymers, star-linear block polymers, densely branched polymers, and dendritic branched polymers based on iterative approach using functionalized 1,1-diphenylethylene derivatives Prog Polym Sci, 2005, 30(2): 111-182

94 Hadjichristidis N, Iatrou H, Pitsikalis M, Mays J. Macromolecular architectures by living and controlled/living polymerizations. Prog Polym Sci, 2006, 31(12): 1068-1132

95 Wyman I, Liu G. Architectural polymers, nanostructures, and hierarchical structures from block copolymers. In Complex macromolecular architectures; Hadjichristidis N, Hirao A, Tezuka Y, Du Prez F, Eds.; John Wiley \& Sons (Asia) Pte Ltd: Singapore, 2011; pp 739-761

96 Liu G. Nanofibers. Adv Mater, 1997, 9(5): 437-439

97 Zhou J, Li Z, Liu G. Diblock copolymer nanospheres with porous cores. Macromolecules, 2002, 35(9): 3690-3696

98 Liu G. Block copolymer nanotubes derived from self-assembly. $A d v$ Polym Sci, 2008, 220: 29-64

99 Wang G, Henselwood F, Liu G. Water-soluble poly(2-cinnamoylethyl methacrylate)-block-poly(acrylic acid) nanospheres as traps for perylene. Langmuir, 1998, 14(7): 1554-1559

100 Zhou Z, Liu G, Han D. Coating and structural locking of dipolar chains of cobalt nanoparticles. ACS Nano, 2009, 3(1): 165-172

101 Liu G, Yan X, Li Z, Zhou J, Duncan S. End coupling of block copolymer nanotubes to nanospheres. J Am Chem Soc, 2003, 125(46): 14039-14045

102 Yan X, Liu G, Li Z. Preparation and phase segregation of block copolymer nanotube multiblocks. J Am Chem Soc, 2004, 126(32): 10059-10066

103 Cameron NS, Corbierre MK, Eisenberg A. 1998 e.W.R. Steacie award lecture asymmetric amphiphilic block copolymers in solution: A morphological wonderland. Can J Chem, 1999, 77(8): 1311-1326

104 Mai Y, Eisenberg A. Self-assembly of block copolymers. Chem Soc Rev, 2012, 41(18): 5969-5985

105 Tuzar Z, Kratochvil P. Block and graft copolymer micelles in solution. Adv Colloid Interface Sci, 1976, 6: 201-232

106 Mortensen K. Structural properties of self-assembled polymeric micelles. Curr Opin Colloid Interface Sci, 1998, 3(1): 12-19

107 Zhulina EB, Borisov OV. Theory of block polymer micelles: Recent advances and current challenges. Macromolecules, 2012, 45(11): 4429-4440

108 Gaucher G, Dufresne M-H, Sant VP, Kang N, Maysinger D, Leroux J-C. Block copolymer micelles: Preparation, characterization and application in drug delivery. J Control Release, 2005, 109(1-3):
169-188

109 Chen Y. Shaped hairy polymer nanoobjects. Macromolecules, 2012, 45(6): 2619-2631

110 Njikang G, Han D, Wang J, Liu G. Abc triblock copolymer micellelike aggregates in selective solvents for a and c. Macromolecules, 2008, 41(24): 9727-9735

111 Luo L, Eisenberg A. One-step preparation of block copolymer vesicles with preferentially segregated acidic and basic corona chains. Angew Chem Int Ed, 2002, 41(6): 1001-1004

112 Gohy JF, Khousakoun E, Willet N, Varshney SK, Jerome R. Segregation of coronal chains in micelles formed by supramolecular interactions. Macromol Rapid Commun, 2004, 25(17): 1536-1539

113 Zhang W, Shi L, An Y, Gao L, He B. Unimacromolucule exchange between bimodal micelles self-assembled by polystyrene-blockpoly(acrylic acid) and polystyrene-block-poly(amino propyleneglycol methacrylate) in water. J Phys Chem B, 2003, 108(1): 200204

114 Xiong Da, He Z, An Y, Li Z, Wang H, Chen X, Shi L. Temperatureresponsive multilayered micelles formed from the complexation of pnipam- $b$-p4vp block-copolymer and ps- $b$-paa core-shell micelles. Polymer, 2008, 49(10): 2548-2552

115 Chang C, Wei H, Li Q, Yang B, Chen N, Zhou J-P, Zhang X-Z, Zhuo RX. Construction of mixed micelle with cross-linked core and dual responsive shells. Polym Chem, 2011, 2(4): 923-930

116 Gohy JF, Varshney SK, Jerome R. Water-soluble complexes formed by poly(2-vinylpyridinium)-block-poly(ethylene oxide) and poly(sodium methacrylate)-block-poly(ethylene oxide) copolymers. Macromolecules, 2001, 34(10): 3361-3366

117 Harada A, Kataoka K. Formation of polyion complex micelles in an aqueous milieu from a pair of oppositely-charged block copolymers with poly(ethylene glycol) segments. Macromolecules, 1995, 28(15): 5294-5299

118 Harada A, Kataoka K. Chain length recognition: Core-shell supramolecular assembly from oppositely charged block copolymers. Science, 1999, 283(5398): 65-67

119 Petrov P, Tsvetanov CB, Jeronme R. Stabilized mixed micelles with a temperature-responsive core and a functional shell. J Phys Chem B, 2009, 113(21): 7527-7533

120 Gao WP, Bai Y, Chen EQ, Li ZC, Han BY, Yang W-T, Zhou Q-F. Controlling vesicle formation via interpolymer hydrogenbonding complexation between poly(ethylene oxide)-block-polybutadiene and poly(acrylic acid) in solution. Macromolecules, 2006, 39(14): 4894-4898

121 Weaver JVM, Armes SP, Liu S. A "holy trinity" of micellar aggregates in aqueous solution at ambient temperature: Unprecedented self-assembly behavior from a binary mixture of a neutral-cationic diblock copolymer and an anionic polyelectrolyte. Macromolecules, 2003, 36(26): 9994-9998

122 Gohy J-F, Varshney SK, Jerome R. Morphology of water-soluble interpolyelectrolyte complexes formed by poly(2-vinylpyridinium)block-poly(ethylene oxide) diblocks and poly(4-styrenesulfonate) polyanions. Macromolecules, 2001, 34(9): 2745-2747

123 Pispas S. Complexes of polyelectrolyte-neutral double hydrophilic block copolymers with oppositely charged surfactant and polyelectrolyte. J Phys Chem B, 2007, 111(29): 8351-8359

124 Attia ABE, Ong ZY, Hedrick JL, Lee PP, Ee PLR, Hammond PT, Yang YY. Mixed micelles self-assembled from block copolymers for drug delivery. Curr Opin Colloid Interface Sci, 2011, 16(3): 182-194

125 Lefèvre N, Fustin CA, Gohy J-F. Polymeric micelles induced by interpolymer complexation. Macromol Rapid Commun, 2009, 30(22): 1871-1888

$126 \mathrm{Hu}$ J, Liu G. Chain mixing and segregation in b-c and c-d diblock copolymer micelles. Macromolecules, 2005, 38(19): 8058-8065

127 Yan X, Liu G, Hu J, Wilson CG. Coaggregation of b-c and d-c diblock copolymers with h-bonding c blocks in block-selective solvents. Macromolecules, 2006, 39(5): 1906-1912

128 Li Z, Kesselman E, Talmon Y, Hillmyer MA, Lodge TP. Multicompartment micelles from abc miktoarm stars in water. 
Science, 2004, 306(5693): 98-101

129 Kabanov AV, Bronich TK, Kabanov VA, Yu K, Eisenberg A. Spontaneous formation of vesicles from complexes of block ionomers and surfactants. J Am Chem Soc, 1998, 120(38): 99419942

130 Bronich TK, Kabanov AV, Kabanov VA, Yu K, Eisenberg A. Soluble complexes from poly(ethylene oxide)-block-polymethacrylate anions and $n$-alkylpyridinium cations. Macromolecules, 1997, 30(12): 3519-3525

131 Bronich TK, Popov AM, Eisenberg A, Kabanov VA, Kabanov AV. Effects of block length and structure of surfactant on self-assembly and solution behavior of block ionomer complexes. Langmuir, 2000, 16(2): 481-489

132 Pochan DJ, Chen Z, Cui H, Hales K, Qi K, Wooley KL. Toroidal triblock copolymer assemblies. Science, 2004, 306(5693): 94-97

133 Cui H, Chen Z, Zhong S, Wooley KL, Pochan DJ. Block copolymer assembly via kinetic control. Science, 2007, 317(5838): 647-650

134 Li Z, Chen Z, Cui H, Hales K, Qi K, Wooley KL, Pochan DJ. Disk morphology and disk-to-cylinder tunability of poly(acrylic acid)- $b$ poly(methyl acrylate)- $b$-polystyrene triblock copolymer solutionstate assemblies. Langmuir, 2005, 21(16): 7533-7539

135 Zhong S, Cui H, Chen Z, Wooley KL, Pochan DJ. Helix selfassembly through the coiling of cylindrical micelles. Soft Matter, 2008, 4(1): 90-93

136 Wang B, Ma R, Liu G, Li Y, Liu X, An Y, Shi L. Glucoseresponsive micelles from self-assembly of poly(ethylene glycol)- $b$ poly(acrylic acid-co-acrylamidophenylboronic acid) and the controlled release of insulin. Langmuir, 2009, 25(21): 12522-12528

137 Yao X, Chen D, Jiang M. Micellization of $\mathrm{ps}-b$-p4vp/formic acid in chloroform without or with the premixing of the copolymer with decanoic acid. Macromolecules, 2004, 37(11): 4211-4217

138 Han P, Li S, Wang C, Xu H, Wang Z, Zhang X, Thomas J, Smet M. Uv-responsive polymeric superamphiphile based on a complex of malachite green derivative and a double hydrophilic block copolymer. Langmuir, 2011, 27(23): 14108-14111

139 Chen S-C, Kuo S-W, Chang F-C. On modulating the self-assembly behaviors of poly(styrene- $b$-4-vinylpyridine)/octyl gallate blends in solution state via hydrogen bonding from different common solvents. Langmuir, 2011, 27(16): 10197-10205

140 Yoshida E, Kunugi S. Micelle formation of nonamphiphilic diblock copolymers through noncovalent bond cross-linking. Macromolecules, 2002, 35(17): 6665-6669

141 Chen D, Jiang M. Strategies for constructing polymeric micelles and hollow spheres in solution via specific intermolecular interactions. Acc Chem Res, 2005, 38(6): 494-502

142 Krappe U, Stadler R, Voigt-Martin I. Chiral assembly in amorphous abc triblock copolymers. Formation of a helical morphology in polystyrene-block-polybutadiene-block-poly(methyl methacrylate) block copolymers. Macromolecules, 1995, 28(13): 4558-4561

143 Cornelissen JJLM, Fischer M, Sommerdijk NAJM, Nolte RJM. Helical superstructures from charged poly(styrene)-poly(isocyanodipeptide) block copolymers. Science, 1998, 280(5368): 1427-1430

144 Geng Y, Discher DE, Justynska J, Schlaad H. Grafting short peptides onto polybutadiene-block-poly(ethylene oxide): A platform for self-assembling hybrid amphiphiles. Angew Chem Int Ed, 2006, 45(45): 7578-7581

145 Xiang H, Shin K, Kim T, Moon SI, McCarthy TJ, Russel TP. From cylinders to helices upon confinement. Macromolecules, 2005, 38(4): 1055-1056

146 Schacher FH, Rudolph T, Drechsler M, Müller AHE. Corecrosslinked compartmentalized cylinders. Nanoscale, 2011, 3(1): 288-297

147 Stadler R, Auschra C, Beckmann J, Krappe U, Voight-Martin I, Leibler L. Morphology and thermodynamics of symmetric poly(ablock-b-block-c) triblock copolymers. Macromolecules, 1995, 28(9): 3080-3097

148 Ho R-M, Chiang YW, Lin S-C, Chen C-K. Helical architectures from self-assembly of chiral polymers and block copolymers. Prog Polym Sci, 2011, 36(3): 376-453
149 Chiang Y-W, Ho R-M, Burger C, Hasegawa H. Helical assemblies from chiral block copolymers. Soft Matter, 2011, 7(21): 9797-9803

150 Yashima E, Maeda K, Iida H, Furusho Y, Nagai K. Helical polymers: Synthesis, structures, and functions. Chem Rev, 2009, 109(11): 6102-6211

151 Wu Y, Cheng G, Katsov K, Sides SW, Wang J, Tang J, Fredrickson GH, Moskovits M, Stucky GD. Composite mesostructures by nano-confinement. Nat Mater, 2004, 3(11): 816-822

152 Jinnai H, Kaneko T, Matsunaga K, Abetz C, Abetz C. A double helical structure formed from an amorphous, achiral abc triblock terpolymer. Soft Matter, 2009, 5(10): 2042-2046

153 Dobriyal P, Xiang H, Kazuyuki M, Chen J-T, Jinnai H, Russell TP. Cylindrically confined diblock copolymers. Macromolecules, 2009, 42(22): 9082-9088

154 Hayward RC, Pochan DJ. Tailored assemblies of block copolymers in solution: It is all about the process. Macromolecules, 2010, 43(8): 3577-3584

155 Pochan DJ, Zhu J, Zhang K, Wooley KL, Miesch C, Emrick T. Multicompartment and multigeometry nanoparticle assembly. Soft Matter, 2011, 7(6): 2500-2506

156 Jain S, Bates FS. Consequences of nonergodicity in aqueous binary peo-pb micellar dispersions. Macromolecules, 2004, 37(4): 15111523

157 Christian DA, Tian A, Ellenbroek WG, Levental I, Rajagopal K, Janmey PA, Liu AJ, Baumgart T, Discher DE. Spotted vesicles, striped micelles and janus assemblies induced by ligand binding. Nat Mater, 2009, 8(10): 843-849

158 Cui H, Chen Z, Wooley KL, Pochan DJ. Origins of toroidal micelle formation through charged triblock copolymer self-assembly. Soft Matter, 2009, 5(6): 1269-1278

159 O'Reilly RK, Hawker CJ, Wooley KL. Cross-linked block copolymer micelles: Functional nanostructures of great potential and versatility Chem Soc Rev, 2006, 35(11): 1068-1083

160 Prochazka K, Baloch MK, Tuzar Z. Photochemical stabilization of block copolymer micelles. Makromol Chem, 1979, 180(10): 25212523

161 Wilson DJ, Riess G. Photochemical stabilization of block copolymer micelles. Eur Polym J, 1988, 24(7): 617-621

162 Kato M, Ichijo T, Ishii K, Hasegawa M. Novel synthesis of photocrosslinkable polymers. J Polym Sci A Polym Chem, 1971, 9(8): 2109-2128

163 Ishizu K, Onen A. Core-shell type polymer microspheres prepared by domain fixing of block copolymer films. J Polym Sci A Polym Chem, 1989, 27(11): 3721-3731

164 Saito R, Ishizu K, Fukutomi T. Crosslinking of the inner poly(methyl methacrylate) core of poly( $\alpha$-methylstyrene- $b$-methyl methacrylate) micelles in selective solvent: 1. Effect of solvent selectivity Polymer, 1990, 31(4): 679-683

165 Ishizu K, Kuwahara K. Organized polymerization of functional diblock copolymers possessing central isoprene groups. J Polym Sci A Polym Chem, 1993, 31(3): 661-665

166 Liu G, Xu X, Skupinska K, Hu N, Yao H. Cross-linked polymer brushes. Ii. Formation and properties of poly(isobutylvinyl ether)-6poly[2-(vinyloxy)ethyl cinnamate] brushes. J Appl Polym Sci, 1994, 53(12): 1699-1707

167 Qiu X, Liu G. Water-dispersible fluorescent nanospheres from poly(solketal acrylate)-block-poly(2-hydroxyethyl acrylate). Polymer, 2004, 45(21): 7203-7211

168 Thurmond II KB, Kowalewski T, Wooley KL. Water-soluble knedel-like structures: The preparation of shell-cross-linked small particles. J Am Chem Soc, 1996, 118(30): 7239-7240

169 Wooley KL. From dendrimers to knedel-like structures. Chem Eur J, 1997, 3(9): 1397-1399

170 Zhang L, Liu W, Lin L, Chen D, Stenzel MH. Degradable disulfide core-cross-linked micelles as a drug delivery system prepared from vinyl functionalized nucleosides via the raft process. Biomacromolecules, 2008, 9(11): 3321-3331

171 Joralemon M, O'Reilly RK, Hawker CJ, Wooley KL. Shell clickcrosslinked (scc) nanoparticles: A new methodology for synthesis 
and orthogonal functionalization. J Am Chem Soc, 2005, 127(48): 16892-16899

172 Feng G, Jia Y, Liu L, Chang W, Li J. Novel organotin-containing shell-cross-linked knedel and core-cross-linked knedel: Synthesis and application in catalysis. J Polym Sci A Polym Chem, 2010, 48(24): 5992-6002

173 Erhardt R, Boker A, Zettl H, Kaya H, Pyckhout-Hintzen W, Krausch G, Abetz V, Müller AHE. Janus micelles. Macromolecules, 2001, 34(4): 1069-1075

174 Gröschel AH, Walther A, Lobling TI, Schmelz J, Hanisch A, Schmalz H, Müller AHE. Facile, solution-based synthesis of soft, nanoscale janus particles with tunable janus balance. J Am Chem Soc, 2012, 134(33): 13850-13860

175 Read ES, Armes SP. Recent advances in shell cross-linked micelles Chem Commun, 2007, (29): 3021-3035

176 van Nostrum CF. Covalently cross-linked amphiphilic block copolymer micelles. Soft Matter, 2011, 7(7): 3246-3259

177 Jeon SJ, Yi GR, Yang SM. Cooperative assembly of block copolymers with deformable interfaces: Toward nanostructured particles. Adv Mater, 2008, 20(21): 4103-4108

178 Utada AS, Lorenceau E, Link DR, Kaplan PD, Stone HA, Weitz DA. Monodisperse double emulsions generated from a microcapillary device. Science, 2005, 308(5721): 537-541

179 Jeon SJ, Yi GR, Koo CM, Yang SM. Nanostructures inside colloidal particles of block copolymer/homopolymer blends. Macromolecules, 2007, 40(23): 8430-8439

180 Tanaka T, Saito N, Okubo M. Control of layer thickness of onionlike multilayered composite polymer particles prepared by the solvent evaporation method. Macromolecules, 2009, 42(19): 7423-7429

181 Schacher FH, Rupar PA, Manners I. Functional block copolymers: Nanostructured materials with emerging applications. Angew Chem Int Ed, 2012, 51(32): 7898-7921

182 Liu G: Block copolymer nanofibers and nanotubes. In Block copolymers in nanoscience; Lazzari M, Liu G, Lecommandoux S, Eds.; Wiley-VCH Verlag GmbH \& Co. KGaG: Weinheim, 2006; pp 233-255

183 Liu G, Yan X, Qiu X, Li Z. Fractionation and solution properties of ps- $b$-pcema- $b$-ptba nanofibers. Macromolecules, 2002, 35(20): $7742-7747$

184 Liu G, Yan X, Duncan S. Polystyrene-block-polyisoprene nanofiber fractions. 1. Preparation and static light-scattering study. Macromolecules, 2002, 35(26): 9788-9793

185 Liu G, Yan X, Duncan S. Polystyrene-block-polyisoprene nanofiber fractions. 2. Viscometric study. Macromolecules, 2003, 36(6): 2049_ 2054

186 Yan X, Liu G, Li H. Preparation, characterization, and solution viscosity of polystyrene-block-polyisoprene nanofiber fractions. Langmuir, 2004, 20(11): 4677-4683

187 Moore WR. Viscosities of dilute polymer solutions. Prog Polym Sci, 1967, 1: 1-43

188 Yamakawa H, Fujii M. Intrinsic viscosity of wormlike chains. Determination of the shift factor. Macromolecules, 1974, 7(1): 128135

189 Yamakawa H, Yoshizaki T. Transport coefficients of helical wormlike chains. 3. Intrinsic viscosity. Macromolecules, 1980, 13(3): 633-643

190 Bohdanecky M. New method for estimating the parameters of the wormlike chain model from the intrinsic viscosity of stiff-chain polymers. Macromolecules, 1983, 16(9): 1483-1492

191 Onsager L. The effects of shape on the interaction of colloidal particles. Ann NY Acad Sci, 1949, 51(May): 627-659

192 Flory PJ. Phase equilibria in solutions of rod-like particles. Proc $R$ Soc London, A: Math Phys Sci, 1956, 234(1196): 73-89

193 Li X, Liu G. Layer-by-layer deposition of block copolymer nanofibers and porous nanofiber multilayer films. Langmuir, 2009, 25(18): 10811-10819

194 Decher G, Hong JD. Buildup of ultrathin multilayer films by a self-assembly process, 1 consecutive adsorption of anionic and cationic bipolar amphiphiles on charged surfaces. Macromol Symp,
1991, 46(1): 321-327

195 Decher G. Fuzzy nanoassemblies: Toward layered polymeric multicomposites. Science, 1997, 277(5330): 1232-1237

196 Ding J, Liu G. Water-soluble hollow nanospheres as potential drug carriers. J Phys Chem B, 1998, 102(31): 6107-6113

197 Cooney DT, Hillmyer MA, Cussler EL, Moggridge GD. Diffusion in nanoporous materials made from block copolymers. Crystallogr Rev, 2006, 12(1): 13-24

198 Phillip WA, Rzayev J, Hillmyer MA, Cussler EL. Gas and water liquid transport through nanoporous block copolymer membranes. $J$ Membr Sci, 2006, 286(1-2): 144-152

199 Phillip WA, O'Neill B, Rodwogin M, Hillmyer MA, Cussler EL. Self-assembled block copolymer thin films as water filtration membranes. ACS Appl Mater Interfaces, 2010, 2(3): 847-853

200 Yan X, Liu G, Liu F, Tang BZ, Peng H, Pakhomov AB, Wong CY. Superparamagnetic triblock copolymer/fe $\mathrm{f}_{2} \mathrm{O}_{3}$ hybrid nanofibers. Angew Chem Int Ed, 2001, 40(19): 3593-3596

201 Li Z, Liu G. Water-dispersible tetrablock copolymer synthesis, aggregation, nanotube preparation, and impregnation. Langmuir, 2003, 19(25): 10480-10486

202 Yan X, Liu G, Haeussler M, Tang BZ. Water-dispersible polymer/ $\mathrm{pd} / \mathrm{ni}$ hybrid magnetic nanofibers. Chem Mater, 2005, 17(24): 6053-6059

203 Underhill RS, Liu G. Preparation and performance of pd particles encapsulated in block copolymer nanospheres as a hydrogenation catalyst. Chem Mater, 2000, 12(12): 3633-3641

204 Lee JS, Hirao A, Nakahama S. Polymerization of monomers containing functional silyl groups. 5. Synthesis of new porous membranes with functional groups. Macromolecules, 1988, 21(1): 274-276

205 Lee JS, Hirao A, Nakahama S. Polymerization of monomers containing functional silyl groups. 7. Porous membranes with controlled microstructures. Macromolecules, 1989, 22(6): 26022606

206 Zhang Q, Remsen EE, Wooley KL. Shell cross-linked nanoparticles containing hydrolytically degradable, crystalline core domains. J Am Chem Soc, 2000, 122(15): 3642-3651

207 Seo M, Amendt MA, Hillmyer MA. Cross-linked nanoporous materials from reactive and multifunctional block polymers. Macromolecules, 2011, 44(23): 9310-9318

208 Huang H, Remsen EE, Kowalewski T, Wooley KL. Nanocages derived from shell cross-linked micelle templates. J Am Chem Soc, 1999, 121(15): 3805-3806

209 Turner JL, Wooley KL. Nanoscale cage-like structures derived from polyisoprene-containing shell cross-linked nanoparticle templates. Nano Lett, 2004, 4(4): 683-688

210 Sanji T, Nakatsuka Y, Ohnishi S, Sakurai H. Preparation of nanometer-sized hollow particles by photochemical degradation of polysilane shell cross-linked micelles and reversible encapsulation of guest molecules. Macromolecules, 2000, 33(23): 8524-8526

211 Hillmyer MA. Nanoporous materials from block copolymer precursors. Adv Polym Sci, 2005, 190: 137-181

212 Olson DA, Chen L, Hillmyer MA. Templating nanoporous polymers with ordered block copolymers. Chem Mater, 2008, 20(3): 869-890

213 Jackson EA, Hillmyer MA. Nanoporous membranes derived from block copolymers: From drug delivery to water filtration. ACS Nano, 2010, 4(7): 3548-3553

214 Lee ES, Na K, Bae YH. Polymeric micelle for tumor ph and folatemediated targeting. J Control Release, 2003, 91(1-2): 103-113

215 Tang BC, Dawson M, Lai SK, Wang Y-Y, Suk JS, Yang M, Zeitlin P, Boyle MP, Fu J, Hanes J. Biodegradable polymer nanoparticles that rapidly penetrate the human mucus barrier. Proc Natl Acad Sci, USA, 2009, 106(46): 19268-19273

216 Sourkohi BK, Cunningham A, Zhang Q, Oh JK. Biodegradable block copolymer micelles with thiol-responsive sheddable coronas. Biomacromolecules, 2011, 12(10): 3819-3825

217 Njikang G, Liu G, Gao J. Preparation and quencher diffusion study of pyrene-tagged water-dispersible abc triblock nanospheres. Macromolecules, 2007, 40(25): 9174-9180 
218 Hoppenbrouwers E, Li Z, Liu G. Triblock nanospheres with amphiphilic coronal chains. Macromolecules, 2003, 36(3): 876-881

219 Koh K, Liu GJ, Wilson CG. Grafting and patterned grafting of block copolymer nanotubes onto inorganic substrates. J Am Chem Soc, 2006, 128(49): 15921-15927

220 Discher DE, Eisenberg A. Polymer vesicles. Science, 2002, 297(5583): 967-973

221 Lorenceau E, Utada AS, Link DR, Cristobal G, Joanicot M, Weitz DA. Generation of polymerosomes from double-emulsions. Langmuir, 2005, 21(20): 9183-9186

222 Boyer C, Whittaker MR, Nouvel C, Davis TP. Synthesis of hollow polymer nanocapsules exploiting gold nanoparticles as sacrificial templates. Macromolecules, 2010, 43(4): 1792-1799

223 Jennings JR, Ghicov A, Peter LM, Schmuki P, Walker AB. Dyesensitized solar cells based on oriented tio $_{2}$ nanotube arrays: Transport, trapping, and transfer of electrons. J Am Chem Soc, 2008, 130(40): 13364-13372

224 Mor GK, Shankar K, Paulose M, Varghese OK, Grimes CA. Use of highly-ordered $\mathrm{tio}_{2}$ nanotube arrays in dye-sensitized solar cells. Nano Lett, 2005, 6(2): 215-218

225 Normile D. Nanotubes generate full-color displays. Science, 1999, 286(5447): 2056-2057

226 Zheng Q, Kang H, Yun J, Lee J, Park JH, Baik S. Hierarchical construction of self-standing anodized titania nanotube arrays and nanoparticles for efficient and cost-effective front-illuminated dye-sensitized solar cells. ACS Nano, 2011, 5(6): 5088-5093

227 Zhu K, Neale NR, Miedaner A, Frank AJ. Enhanced chargecollection efficiencies and light scattering in dye-sensitized solar cells using oriented $\mathrm{tio}_{2}$ nanotubes arrays. Nano Lett, 2006, 7(1): 69-74

228 Hasobe T, Fukuzumi S, Kamat PV. Stacked-cup carbon nanotubes for photoelectrochemical solar cells. Angew Chem Int Ed, 2006, 45(5): 755-759

229 Avouris P. Molecular electronics with carbon nanotubes. Acc Chem Res, 2002, 35(12): 1026-1034

230 Collins PG, Arnold MS, Avouris P. Engineering carbon nanotubes and nanotube circuits using electrical breakdown. Science, 2001, 292(5517): 706-709

231 Halford B. Nanotube catalysts. Chemical \& Engineering News, 2009, 87(6): 7

232 Pan X, Bao X. The effects of confinement inside carbon nanotubes on catalysis. Acc Chem Res, 2011, 44(8): 553-562

233 Martin CR, Kohli P. The emerging field of nanotube biotechnology. Nat Rev Drug Discov, 2003, 2(1): 29-37

234 Organo VG, Rudkevich DM. Emerging host-guest chemistry of synthetic nanotubes. Chem Commun, 2007, (38): 3891-3899

235 Yin YF, Mays T, McEnaney B. Adsorption of nitrogen in carbon nanotube arrays. Langmuir, 1999, 15(25): 8714-8718

236 Pascal TA, Goddard WA, Jung Y. Entropy and the driving force for the filling of carbon nanotubes with water. Proc Natl Acad Sci, USA, 2011, 108(29): 11794-11798

237 Iijima S. Helical microtubules of graphitic carbon. Nature, 1991, 354(6348): 56-58

238 Tasis D, Tagmatarchis N, Bianco A, Prato M. Chemistry of carbon nanotubes. Chem Rev, 2006, 106(3): 1105-1136

239 Hu L, Hecht DS, Gruner G. Carbon nanotube thin films: Fabrication, properties, and applications. Chem Rev, 2010, 110(10): 5790-5844

240 Zhou O, Shimoda H, Gao B, Oh S, Fleming L, Yue G. Materials science of carbon nanotubes: Fabrication, integration, and properties of macroscopic structures of carbon nanotubes. Acc Chem Res, 2002, 35(12): 1045-1053

241 Ebbesen TW, Ajayan PM. Large-scale synthesis of carbon nanotubes. Nature, 1992, 358(6383): 220-222

242 Liu Z, Misra M. Dye-sensitized photovoltaic wires using highly ordered $\mathrm{tio}_{2}$ nanotube arrays. ACS Nano, 2010, 4(4): 2196-2200

243 Qiao Y, Wang Y, Yang Z, Lin Y, Huang J. Self-templating of metaldriven supramolecular self-assembly: A general approach toward 1d inorganic nanotubes. Chem Mater, 2011, 23(5): 1182-1187

244 Zhou M, Zhu H, Wang X, Xu Y, Tao Y, Hark S, Xiao X, Li Q. Cdse nanotube arrays on ito via aligned zno nanorods templating. Chem Mater, 2009, 22(1): 64-69

245 Kol N, Adler-Abramovich L, Barlam D, Shneck RZ, Gazit E, Rousso I. Self-assembled peptide nanotubes are uniquely rigid bioinspired supramolecular structures. Nano Lett, 2005, 5(7): 13431346

246 Brea RJ, Reiriz C, Granja JR. Towards functional bionanomaterials based on self-assembling cyclic peptide nanotubes. Chem Soc Rev, 2010, 39(5): 1448-1456

247 Amdursky N, Molotskii M, Gazit E, Rosenman G. Elementary building blocks of self-assembled peptide nanotubes. J Am Chem Soc, 2010, 132(44): 15632-15636

248 Amdursky N, Beker P, Koren I, Bank-Srour B, Mishina E, Semin S, Rasing T, Rosenberg Y, Barkay Z, Gazit E, Rosenman G. Structural transition in peptide nanotubes. Biomacromolecules, 2011, 12(4): 1349-1354

249 Hourani R, Zhang C, van der Weegen R, Ruiz L, Li C, Keten S, Helms BA, Xu T. Processable cyclic peptide nanotubes with tunable interiors. J Am Chem Soc, 2011, 133(39): 15296-15299

250 Reches M, Gazit E. Casting metal nanowires within discrete self-assembled peptide nanotubes. Science, 2003, 300(5619): 625627

251 Song Y, Challa SR, Medforth CJ, Qiu Y, Watt RK, Peña D, Miller JE, van Swol F, Shelnutt JA. Synthesis of peptide-nanotube platinum-nanoparticle composites. Chem Commun, 2004, (9): 10441045

252 Tarabout C, Roux S, Gobeaux F, Fay N, Pouget E, Meriadec C, Ligeti M, Thomas D, IJsselstijn M, Besselievre F, Buisson D-A, Verbavatz J-M, Petitjean M, Valéry C, Perrin L, Rousseau B, Artzner F, Paternostre M, Cintrat J-C. Control of peptide nanotube diameter by chemical modifications of an aromatic residue involved in a single close contact. Proc Natl Acad Sci, USA, 2011, 108(19): 7679-7684

253 Smirnov AI, Poluektov OG. Substrate-supported lipid nanotube arrays. J Am Chem Soc, 2003, 125(28): 8434-8435

254 Karp ES, Inbaraj JJ, Laryukhin M, Lorigan GA. Electron paramagnetic resonance studies of an integral membrane peptide inserted into aligned phospholipid bilayer nanotube arrays. J Am Chem Soc, 2006, 128(37): 12070-12071

255 Xiao R, Cho SI, Liu R, Lee SB. Controlled electrochemical synthesis of conductive polymer nanotube structures. J Am Chem Soc, 2007, 129(14): 4483-4489

$256 \mathrm{Yu} \mathrm{K,} \mathrm{Zhang} \mathrm{L,} \mathrm{Eisenberg} \mathrm{A.} \mathrm{Novel} \mathrm{morphologies} \mathrm{of} \mathrm{"crew-cut"}$ aggregates of amphiphilic diblock copolymers in dilute solution. Langmuir, 1996, 12(25): 5980-5984

$257 \mathrm{Yu} \mathrm{K}$, Eisenberg A. Bilayer morphologies of self-assembled crewcut aggregates of amphiphilic ps- $b$-peo diblock copolymers in solution. Macromolecules, 1998, 31(11): 3509-3518

258 Tian Z, Le H, Wang M, Zhang A, Feng Z-G. Vesicular and tubular structures prepared from self-assembly of novel amphiphilic aba triblock copolymers in aqueous solutions. J Polym Sci A Polym Chem, 2008, 46(3): 1042-1050

259 Raez J, Manners I, Winnik MA. Nanotubes from the self-assembly of asymmetric crystalline-coil poly(ferrocenylsilane-siloxane) block copolymers. J Am Chem Soc, 2002, 124(35): 10381-10395

260 Frankowski DJ, Raez J, Manners I, Winnik MA, Khan SA, Spontak RJ. Formation of dispersed nanostructures from poly(ferrocenyldimethylsilane- $b$-dimethylsiloxane) nanotubes upon exposure to supercritical carbon dioxide. Langmuir, 2004, 20(21): 9304-9314

261 Grumelard J, Taubert A, Meier W. Soft nanotubes from amphiphilic aba triblock macromonomers. Chem Commun, 2004, (13): 14621463

262 Wan WM, Pan CY. One-pot synthesis of polymeric nanomaterials via raft dispersion polymerization induced self-assembly and re-organization. Polym Chem, 2010, 1(9): 1475-1484

263 Jia L, Lévy D, Durand D, Impéror-Clerc M, Cao A, Li M-H. Smectic polymer micellar aggregates with temperature-controlled morphologies. Soft Matter, 2011, 7(16): 7395-7403

264 Kim Y, Dalhaimer P, Christian DA, Discher DE. Polymeric worm 
micelles as nano-carriers for drug delivery. Nanotechnology, 2005, 16(7): S484-S491

265 Geng Y, Discher DE. Hydrolytic degradation of poly(ethylene oxide)-block-polycaprolactone worm micelles. J Am Chem Soc, 2005, 127(37): 12780-12781

266 Geng Y, Discher DE. Visualization of degradable worm micelle breakdown in relation to drug release. Polymer, 2006, 47(7): 25192525

267 Kang M, Moon B. Synthesis of photocleavable poly(styrene-blockethylene oxide) and its self-assembly into nanoporous thin films. Macromolecules, 2009, 42(1): 455-458

268 Schumers J-M, Gohy J-F, Fustin C-A. A versatile strategy for the synthesis of block copolymers bearing a photocleavable junction. Polym Chem, 2010, 1(2): 161-163

269 Takae S, Miyata K, Oba M, Ishii T, Nishiyama N, Itaka K, Yamasaki Y, Koyama H, Kataoka K. Peg-detachable polyplex micelles based on disulfide-linked block catiomers as bioresponsive nonviral gene vectors. J Am Chem Soc, 2008, 130(18): 6001-6009

270 Cerritelli S, Velluto D, Hubbell JA. Peg-ss-pps: Reduction-sensitive disulfide block copolymer vesicles for intracellular drug delivery. Biomacromolecules, 2007, 8(6): 1966-1972

271 Goldbach JT, Russell TP, Penelle J. Synthesis and thin film characterization of poly(styrene-block-methyl methacrylate) containing an anthracene dimer photocleavable junction point. Macromolecules, 2002, 35(11): 4271-4276

272 Goldbach JT, Lavery KA, Penelle J, Russell TP. Nano- to macro-sized heterogeneities using cleavable diblock copolymers. Macromolecules, 2004, 37(25): 9639-9645

273 Tang L-Y, Wang Y-C, Li Y, Du J-Z, Wang J. Shell-detachable micelles based on disulfide-linked block copolymer as potential carrier for intracellular drug delivery. Bioconjugate Chem, 2009, 20(6): 1095-1099

274 Wang K, Liu Y, Yi W-J, Li C, Li Y-Y, Zhuo R-X, Zhang X-Z. Novel shell-cross-linked micelles with detachable peg corona for glutathione-mediated intracellular drug delivery. Soft Matter, 2013, 9(3): 692-699

275 Yurt S, Anyanwu UK, Scheintaub JR, Coughlin EB, Venkataraman D. Scission of diblock copolymers into their constituent blocks. Macromolecules, 2006, 39(5): 1670-1672

276 Zhang M, Yang L, Yurt S, Misner MJ, Chen J-T, Coughlin EB, Venkataraman D, Russell TP. Highly ordered nanoporous thin films from cleavable polystyrene-block-poly(ethylene oxide). Adv Mater, 2007, 19(12): 1571-1576

277 Lin S, Du F, Wang Y, Ji S, Liang D, Yu L, Li Z. An acid-labile block copolymer of pdmaema and peg as potential carrier for intelligent gene delivery systems. Biomacromolecules, 2008, 9(1): 109-115

278 Bang J, Kim SH, Drockenmuller E, Misner MJ, Russell TP, Hawker CJ. Defect-free nanoporous thin films from abc triblock copolymers. J Am Chem Soc, 2006, 128(23): 7622-7629

279 Han D, Tong X, Zhao Y. Fast photodegradable block copolymer micelles for burst release. Macromolecules, 2011, 44(3): 437-439

280 Han D, Tong X, Zhao Y. Block copolymer micelles with a dual-stimuli-responsive core for fast or slow degradation. Langmuir, 2012, 28(5): 2327-2331

281 Theato P. One is enough: Influencing polymer properties with a single chromophoric unit. Angew Chem Int Ed, 2011, 50(26): 58045806

282 Cabane E, Malinova V, Meier W. Synthesis of photocleavable amphiphilic block copolymers: Toward the design of photosensitive nanocarriers. Macromol Chem Phys, 2010, 211(17): 1847-1856

283 Zhao H, Gu W, Sterner E, Russell TP, Coughlin EB, Theato P. Highly ordered nanoporous thin films from photocleavable block copolymers. Macromolecules, 2011, 44(16): 6433-6440

284 Schumers J-M, Fustin C-A, Gohy J-F. Light-responsive block copolymers. Macromol Rapid Commun, 2010, 31(18): 1588-1607

285 Zhao Y. Photocontrollable block copolymer micelles: What can we control? J Mater Chem, 2009, 19(28): 4887-4895

286 Zhao Y. Light-responsive block copolymer micelles. Macromolecules,
2012, 45(9): 3647-3657

287 Zhao H, Sterner ES, Coughlin EB, Theato P. $O$-nitrobenzyl alcohol derivatives: Opportunities in polymer and materials science. Macromolecules, 2012, 45(4): 1723-1736

288 Holmes CP. Model studies for new o-nitrobenzyl photolabile linkers: Substituent effects on the rates of photochemical cleavage. $J$ Org Chem, 1997, 62(8): 2370-2380

289 Xue Z, Liu M, Jiang L. Recent developments in polymeric superoleophobic surfaces. J Polym Sci B Polym Phys, 2012, 50(17): 1209-1224

290 Rabnawaz M, Liu G. Preparation and application of a dual lightresponsive triblock terpolymer. Macromolecules, 2012, 45(13): 5586-5595

291 Tezuka Y, Oike H. Topological polymer chemistry. Prog Polym Sci, 2002, 27(6): 1069-1122

292 Tezuka Y. Topological polymer chemistry by electrostatic selfassembly. J Polym Sci A Polym Chem, 2003, 41(19): 2905-2917

293 Tezuka Y. Topological polymer chemistry by dynamic selection from electrostatic polymer self-assembly. Chem Rec, 2005, 5(1): $17-26$

294 Hirao A, Murano K, Oie T, Uematsu M, Goseki R, and Yuri Matsuo Y. Chain-end- and in-chain-functionalized ab diblock copolymers as key building blocks in the synthesis of well-defined architectural polymers. Polym Chem, 2011, 2(6): 1219-1233

295 Pyun J, Tang C, Kowalewski T, Frechet JMJ, Hawker CJ. Synthesis and direct visualization of block copolymers composed of different macromolecular architectures. Macromolecules, 2005, 38(7): 26742685

296 Dong Y-Q, Tong Y-Y, Dong B-T, Du F-S, Li Z-C. Preparation of tadpole-shaped amphiphilic cyclic ps- $b$-linear peo via atrp and click chemistry. Macromolecules, 2009, 42(8): 2940-2948

297 Wulff G, Sarhan A. The use of polymers with enzyme-analogous structures for the resolution of racemates. Angew Chem Int Ed Engl, 1972, 11(4): 341

298 Wulff G. Molecular imprinting in cross-linked materials with the aid of molecular templates-a way towards artificial antibodies. Angew Chem Int Ed, 1995, 34(17): 1812-1832

299 Sellergren B. Imprinted chiral stationary phases in high-performance liquid chromatography. J Chromatogr A, 2001, 906(1-2): 227-252

300 Lepistoe M, Sellergren B. Discrimination between amino acid amide conformers by imprinted polymers. J Org Chem, 1989, 54(26): 6010-6012

301 Carboni D, Flavin K, Servant A, Gouverneur V, Resmini M. The first example of molecularly imprinted nanogels with aldolase type $\mathrm{i}$ activity. Chem Eur J, 2008, 14(23): 7059-7065

302 Karlsson BCG, Rosengren AM, Naslund I, Andersson PO, Nicholls IA. Synthetic human serum albumin sudlow i binding site mimics. $J$ Med Chem, 2010, 53(22): 7932-7937

303 Bui BTS, Merlier F, Haupt K. Toward the use of a molecularly imprinted polymer in doping analysis: Selective preconcentration and analysis of testosterone and epitestosterone in human urine. Anal Chem, 2010, 82(11): 4420-4427

304 Stringer RC, Gangopadhyay S, Grant SA. Detection of nitroaromatic explosives using a fluorescent-labeled imprinted polymer. Anal Chem, 2010, 82(10): 4015-4019

305 Apodaca DC, Pernites RB, Del Mundo FR, Advincula RC. Detection of 2,4-dinitrotoluene (dnt) as a model system for nitroaromatic compounds via molecularly imprinted short-alkyl-chain sams. Langmuir, 2011, 27(11): 6768-6779

306 ten Brinke G, Loos K, Vukovic I, du Sart GG. Hierarchical self-assembly of two-length-scale multiblock copolymers. $J$ Phys: Condens Matter, 2011, 23(28): 284110/284111-284116

307 Li X, Liu G, Han D. Wrapping amino-bearing block copolymer cylinders around carboxyl-bearing nanofibers: A case of hierarchical assembly. Soft Matter, 2011, 7(18): 8216-8223

308 Nie L, Liu S, Shen W, Chen D, Jiang M. One-pot synthesis of amphiphilic polymeric janus particles and their self-assembly into supermicelles with a narrow size distribution. Angew Chem Int Ed, 2007, 46(33): 6321-6324 
309 Wang X, Guerin G, Wang H, Wang Y, Manners I, Winnik MA. Cylindrical block copolymer micelles and co-micelles of controlled length and architecture. Science, 2007, 317(5838): 644-657

$310 \mathrm{He}$ W-N, Xu J-T. Crystallization assisted self-assembly of semicrystalline block copolymers. Prog Polym Sci, 2012, 37(10): $1350-1400$

311 Massey JA, Temple K, Cao L, Rharbi Y, Raez J, Winnik MA, Manners I. Self-assembly of organometallic block copolymers: The role of crystallinity of the core-forming polyferrocene block in the micellar morphologies formed by poly(ferrocenylsilane- $b$-dimethylsiloxane) in $n$-alkane solvents. J Am Chem Soc, 2000, 122(47): 11577-11584
312 novel organometallic-inorganic block copolymer in solution and the solid state: Nonintrusive observation of novel wormlike poly(ferrocenyldimethylsilane)- $b$-poly(dimethylsiloxane) micelles. $J$ Am Chem Soc, 1998, 120(37): 9533-9540

313 Patra SK, Ahmed R, Whittell GR, Lunn DJ, Dunphy EL, Winnik MA, Manners I. Cylindrical micelles of controlled length with a $\pi$-conjugated polythiophene core via crystallization-driven selfassembly. J Am Chem Soc, 2011, 133(23): 8842-8845

314 Gao Y, Li X, Hong L, Liu G. Mesogen-driven formation of triblock copolymer cylindrical micelles. Macromolecules, 2012, 45(3): 13211330
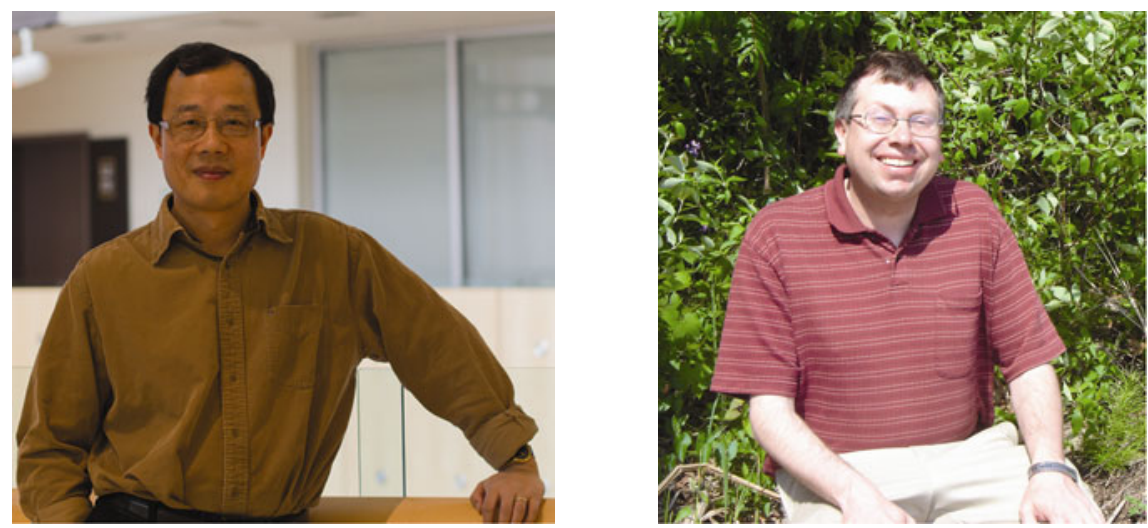

LIU Guojun (left) received his B.Sc. degree from Nankai University, China, and his M.Sc. and Ph.D. degrees from the University of Toronto. After his post-doctoral research at the University of Toronto and McGill University, he joined the University of Calgary as an Assistant Professor in 1990. There, he rose to the ranks of Associate and Full Professor in 1995 and 1999, respectively. In 2004, he joined Queen's University as a Tier I Canada Research Chair in Materials Science. His current research interests are in the preparation, study, and application of architectured materials of block copolymers.

WYMAN Ian (right) received a B.Sc. at Dalhousie University, a M.Sc. in Inorganic Chemistry at St. Francis Xavier University in 2004 under the supervision of Prof. Manuel Aquino. Subsequently, he obtained a Ph.D. in Supramolecular Chemistry from Queen's University under the supervision of Prof. Donal Macartney in 2010. He is currently a postdoctoral researcher in Prof. Guojun Liu's lab. His research interests include supramolecular chemistry, transition metal chemistry, physical organic chemistry, and block copolymer self-assembly. 